\title{
Parcelaciones funerarias en necrópolis cordubenses. Reflexiones a partir de dos hallazgos recientes*
}

\section{Funerary enclosures in necropolises from Córdoba. Reflections based on two recent findings}

\author{
Desiderio Vaquerizo Gil ${ }^{1}$ \\ Universidad de Córdoba
}

\begin{abstract}
RESUMEN
Este trabajo ofrece una aproximación al paisaje de las áreas funerarias cordubenses de época altoimperial, sometidas a los vaivenes propios de una ciudad viva, en expansión y contracción alternas según las épocas, y objeto más que posible de especulación supuesto el sacrificio que representaba dedicar terrenos suburbanos de enorme potencial económico a fines funerarios y el alto precio consecuente de los loci. Creemos, de hecho, haber detectado ejemplos claros de lotizaciones bien planificadas en forma de recintos y acotados reforzados de forma ocasional mediante el uso de mensurae sepulcri, que analizamos a través de dos sepulcreta especialmente significativos excavados hace solo unos años.
\end{abstract}

\section{SUMMARY}

Our work brings an approach to the landscape of Corduba's funerary areas during the High Imperial Period, subjected to the vicissitudes of a living city which alternated moments of expansion and contraction. This landscape probably was also object of strong speculation, given the sacrifice involved in dedicating suburban land of enormous economic potential for funerary purposes, and the consequent high price of loci. At this respect, we believe to have detected clear examples of wellplanned divisions of the terrain into lots in the form of enclosures, occasionally reinforced by mensurae sepulcri. All

* Este trabajo se inscribe en el marco del Proyecto de I+D+i PATTERN (Ref. HAR2015-68059-C2-1-R), concedido por el Ministerio de Economía y Competitividad para el trienio 20162019, conmigo como Investigador Principal. También se enmarca en el Proyecto de Excelencia del P.A.I. CVB I, que sostiene la Universidad de Huelva bajo la dirección de J.M. Campos Carrasco.

Gracias a Ana Ruiz, Sergio García-Dils, Carmen González y Manuel D. Ruiz-Bueno por su apoyo en diferentes momentos y aspectos de mi investigación. También, a Manuel Rubio, Agustín López, Sonia Vargas, y todos aquellos arqueólogos que me han cedido información para este trabajo.

${ }^{1}$ dvaquerizo@uco.es / ORCID iD: https://orcid.org/00000002-8604-958X this is analyzed through two especially significant sepulcreta recently excavated.

PALABRAS CLAVE: Corduba; Colonia Patricia; necrópolis; vías sepulcrales; topografía; recintos; mensurae sepulcri; pedatura; lotización.

KEY WORDS: Corduba; Colonia Patricia; necropolis; viae sepulchrales; topography; enclosures; mensurae sepulcri; pedatura; division into lots.

CÓMO CITAR ESTE ARTÍCULO / CITATION: Vaquerizo Gil, D. 2020: "Parcelaciones funerarias en necrópolis cordubenses. Reflexiones a partir de dos hallazgos recientes", Archivo Español de Arqueología 93, 147-172. https://doi.org/10.3989/aespa.093.020.007

\section{INTRODUCCIÓN}

Las áreas sepulcrales cordubenses, dispuestas desde muy pronto en torno a las vías principales de salida y entrada en la ciudad, conocieron en época altoimperial una cierta sobreocupación de la que derivaron un alto valor económico y social del terreno y, en consecuencia, frecuentes parcelaciones del mismo en lotes de tamaños variables aunque por lo general bastante reducidos, perfectamente equiparables a los que se documentan en otras ciudades de Occidente, como Roma y Ostia Antica en Italia, o Astigi y Augusta Emerita en Hispania. Tales lotizaciones -privadas, y quizás también públicas-, tomaron forma en acotados funerarios a cielo abierto, señalizados mediante muy diversos métodos e insertos en un paisaje sepulcral complejo y mutable. Hasta la fecha hemos detectado recintos de obra, o en su defecto termini con mención epigráfica expresa de mensurae sepulcri, in situ o descontextualizados, distribuidos en las necrópolis occi-

Copyright: ( 2020 CSIC. Este es un artículo de acceso abierto distribuido bajo los términos de una licencia de uso y distribución Creative Commons Reconocimiento 4.0 Internacional (CC-by 4.0). 
dental, septentrional y oriental -en la meridional, menos ocupada, las cosas funcionan de forma algo diferente-, y son infinidad los ejemplos conocidos (Vaquerizo y Sánchez 2008 y 2009) (Fig. 1), pendientes de un nuevo trabajo de sistematización e inventario (vid. como acercamientos al tema más recientes Vaquerizo et alii 2019 y e. p., o Vaquerizo e. p.).

En la necrópolis occidental destacan, entre otros:

- Puerta de Gallegos (s. I a. C.): recintos de planta rectangular, con muros bajos de adobe sobre zócalos de piedra, orientados norte-sur o este-oeste, y dispuestos de forma prácticamente ortogonal dando fachada a la via Corduba-Hispalis, al lado mismo de la porta occidentalis (Murillo y Carrillo 1999; Murillo et alii 2002);

- Camino Viejo de Almodóvar (s. I d. C.): $s e$ pulcretum estructurado en torno a ambos márgenes de un ramal de la vía Corduba-Hispalis, y conformado, entre otros monumentos y tipos de tumba, por una docena de presuntos recintos funerarios, no todos contiguos, construidos con materiales diversos entre los que predomina la sillería, incluso almohadillada (Ruiz Osuna 2018: 198 ss.);

- Avenida del CorRegidor: en la zona suroccidental de la ciudad, muy cerca del Baetis, se construyeron en época augustea tres recintos funerarios pavimentados mediante niveles de albero o picadura de sillar, y combinados con toda una serie de cipos en calcarenita y caliza violácea que delimitaban otros loci (Vargas y Gutiérrez 2006: 274);

- GlORIETA DE IBN ZAYdun: allí fueron excavados dos monumentos funerarios y un recinto contiguo de unos 15 pies de lado, que abrían en fachada a un posible diverticulum de la via Corduba-Hispalis, dotados de pozo, varias estructuras hidráulicas y un posible hortus en su parte posterior (Ruiz Osuna 2007a: 65 ss.).

La necrópolis septentrional fue, por su parte, uno de los sectores cementeriales más tempranamente ocupados, más complejos y de mayor densidad de la ciudad, en directa relación con las vías de acceso al distrito minero y la metalurgia de la plata; de ahí la

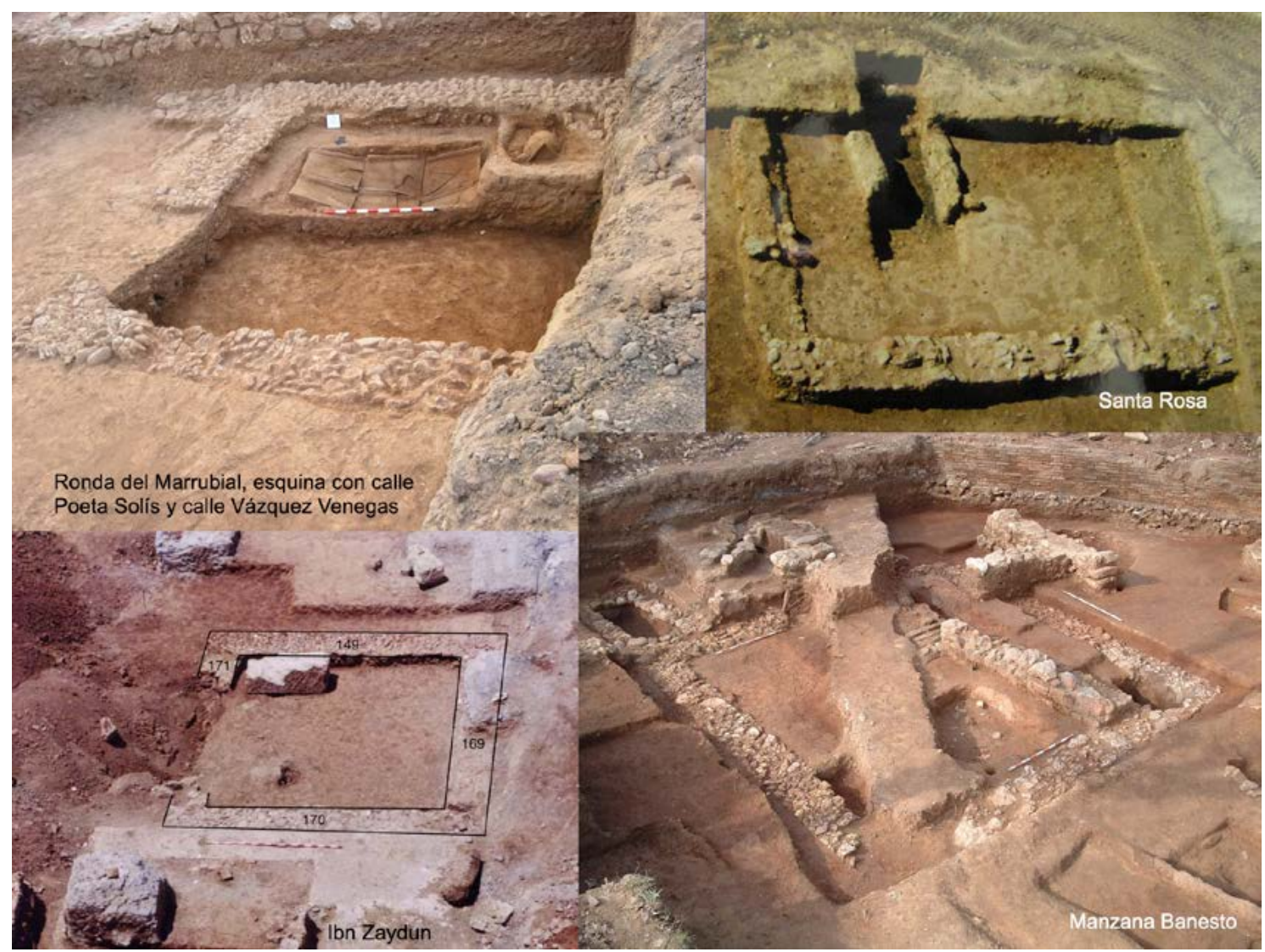

Figura 1. Recintos funerarios de época romana documentados en diversos sectores funerarios de Córdoba (fotografías de autoría diversa). 
recuperación en la zona de tituli sepulcrales de miembros de societates mineras y metalúrgicas $\left(C I L \mathrm{II}^{2} / 7\right.$, 334, o $C I L I^{2} / 7$, 415a). Su abigarrado paisaje funerario queda representado desde el punto de vista que nos interesa por, entre otros conjuntos:

- La CONSTANCIA: siete recintos de planta rectangular dispuestos en torno a calles y espacios abiertos de uso específicamente funerario, similares a los ob- fachada una batería de recintos de dimensiones indeterminadas, por el norte, y un ustrinum en fosa revestida de opus caementicium, por el sur. Tales espacios funerarios debieron estar en uso entre mediados del siglo I e inicios del siglo III d. C., a juzgar por el material cerámico y los restos de epigrafía recuperados: fragmentos correspondientes cuando menos a trece individuos (Molina Mahedero 2005²).
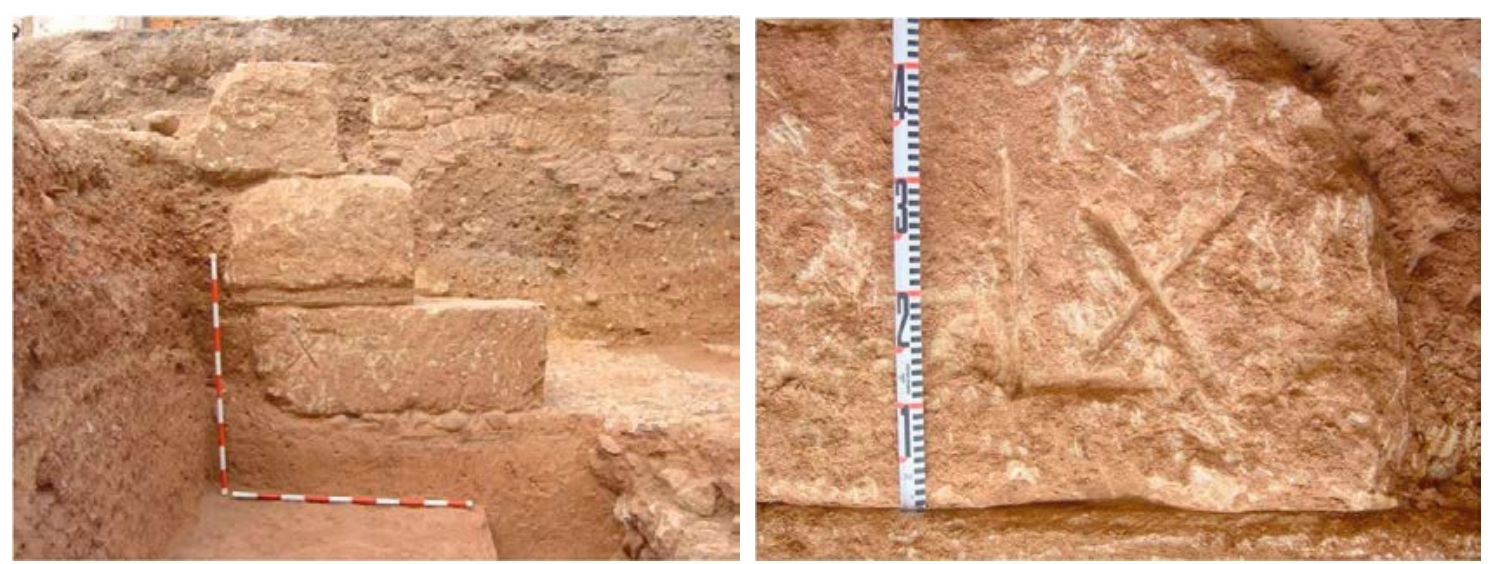

Figura 2. Muro de la Misericordia. Supuesta marca de cantero. A) Localización. B) Detalle (fotografía J. A. Molina Mahedero).

servados en otras necrópolis con sectores bien parcelados y sistematizados (Cipriano 2005: 278; Cebrián y Hortelano 2016: 44). Los enterramientos, en su mayoría de cremación y fechados entre los siglos I y II d. C. (Vaquerizo et alii 2005), aparecen tanto dentro como fuera de las estructuras.

- C/ Abderramán III-Centro de Salud HuerTA DE LA REINA: casi una decena de recintos funerarios de dimensiones indeterminadas, abiertos a una vía con orientación norte-sur, tal vez prolongación de la excavada en La Constancia. El complejo, de la primera mitad del siglo I d. C., sería reocupado años más tarde por enterramientos de inhumación que parecen convivir con usos industriales (Salinas Pleguezuelo 2015).

Por último, en la necrópolis oriental destacan:

- Calle Muñices esquina con Plaza de la MAGDALENA: empedrados con fachadas de unos 25 pies, dispuestos de forma paralela a la via Augusta vetus, que acogían en su interior monumentos funerarios de gran porte tipo edicola (Ruiz Osuna 2007a: 58 y 67 ss.).

- Muro de la Misericordia ESQuina con CALle PAlomares: vía de 21 pies de anchura con andenes escalonados de opus quadratum - uno de los sillares utilizados para tal fin, dispuesto boca abajo, llevaba grabadas dos letras: $L X$, que el excavador interpretó como marca de taller (Fig. 2)-, a la que daban
A todos estos conjuntos se añaden dos que, por su especial relevancia y su riqueza en información, analizaré de manera monográfica a fin de ilustrar con detalle una problemática arqueológica sobre la que terminaré aportando algunas reflexiones generales en aras de ir poco a poco clarificando el fenómeno, en la ciudad de Córdoba y no solo. Ambos se inscriben en el marco de la necrópolis septentrional.

\section{AVENIDA DE LAS OLLERÍAS}

El sepulcretum -avances en López Jiménez inédito $^{3}$ y 2010; Ruiz Osuna 2007b: 34 ss. y 2008; o Vaquerizo 2010: 110 ss.-, que proporcionó una cincuentena de tumbas esencialmente inéditas, centradas en la

\footnotetext{
2 Molina Mahedero, J. A. 2005: Informe Preliminar de la Actividad Arqueológica Preventiva en la Calle Muro de la Misericordia esquina con Calle Palomares (Córdoba). Informe administrativo inédito, depositado en la Gerencia Municipal de Urbanismo del Ayuntamiento de Córdoba, donde ha sido consultado.

${ }^{3}$ López Jiménez, A. 2006: Informe y Memoria. Parcela 4 del Plan Especial SC-2a, 06, Delegación Provincial de Cultura de la Junta de Andalucía en Córdoba. Informe inédito cedido por el autor, a quien agradezco la generosidad con que siempre me ha regalado.
} 
primera mitad del siglo I d. C., se estructuraba en torno a una via sepulcralis con orientación suroestenordeste que servía de eje rector del complejo funerario, si bien diversos datos, como la perfecta planificación de la zona, la posible alusión en la epigrafía conservada a una numeración de la misma (vid. infra), o el hecho de que el Recinto 4 se ubicara unos quince metros al sur de la alineación principal, permiten suponer la existencia de otras (Fig. 3).

Se localiza circa una milla romana de la puerta norte de la ciudad, según sus excavadores en las proximidades del ramal de la via Augusta que, según viene aceptando tradicionalmente la investigación al uso, entraba en la colonia por esta zona, quizá fosilizado en la misma Avenida de las Ollerías (Melchor 1995: 79 ss.) -a lo largo de tres millas en torno a los ejes principales de comunicación se extendían las necrópolis en Aquileia (Zaccaria 2005), y hasta tres kilómetros en Altinum (Tirelli 2005: 253)-. Tal circunstancia habría incrementado de manera exponencial el interés social por enterrarse en sus proximidades, y también el valor económico de los terrenos. Las cosas, sin embargo, no parecen estar tan claras si nos para- mos a analizar la información arqueológica sobre la que ha sido reconstruida la red viaria cordubense (Fig. 4): los tramos bien documentados y con un trazado mínimamente seguro son muy pocos (Ruiz Bueno e. p.), lo que convierte dicha propuesta en una simple hipótesis de trabajo.

Con los datos existentes, y sin descartar nada, hemos de interpretar en principio la vía a la que abren los recintos como un diverticulum de finalidad estrictamente cementerial destinado a sistematizar y "urbanizar" -facilitando de paso su división en lotes- la topografía funeraria de la zona, cuyo alto valor confirmaría además el pequeño tamaño de los recintos; con independencia de que sus superficies pudieran haber sido consideradas más o menos tipo, y no se plantearan mayores porque no había costumbre ni tampoco fuera necesario. En la misma Roma se observa, de hecho, una cierta estandarización de las mismas, con tendencia a loci cuadrados, o en su defecto rectangulares, y predominio claro del módulo de $12 \times$ 12 pies. En cualquier caso, la variedad es amplia (Gregori 2005: 90 ss.), como ocurre en zonas del norte de Italia, donde las áreas medias documentadas suelen

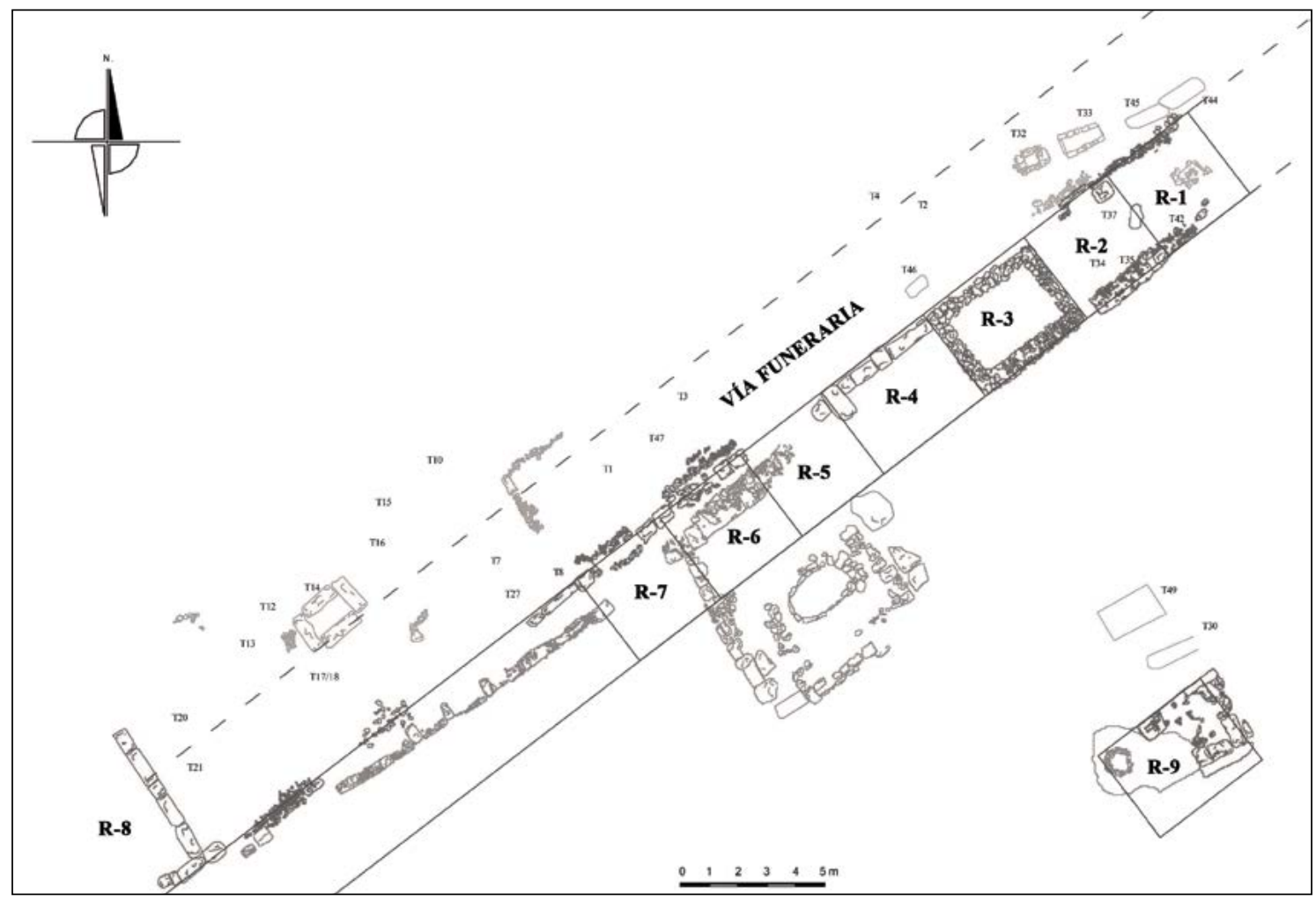

Figura 3. Avenida de las Ollerías. Planta general del sepulcretum (a partir de López Jiménez 2006, con apoyo de G. García Vegas y M. Ruiz Bueno). 


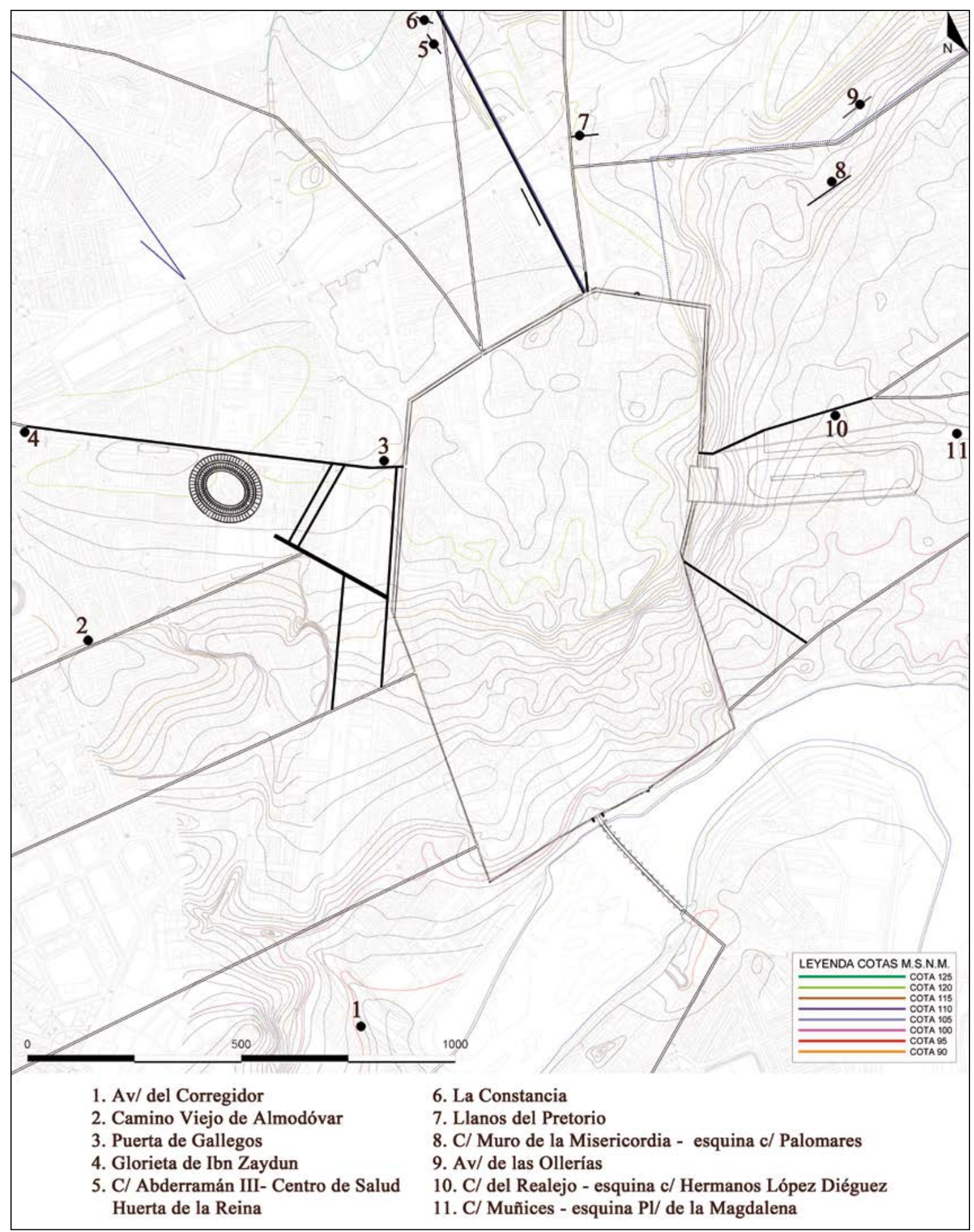

Figura 4. Localización topográfica de las vías y los principales conjuntos funerarios citados en el texto (elaboración M.D. Ruiz Bueno).

ser algo más grandes, sobre todo en ámbitos rurales (Liguori 2005). En Altinum, por ejemplo, con recintos algo más grandes de lo habitual, predomina el módulo de 20 pies in fronte por 30 in agro, base de una 
cierta planificación, muy posiblemente privada, que habría intentado dar al mayor número de ellos fachada a la vía (Buonopane y Mazzer 2005: 331 ss.). La cuestión debe, pues, ser tratada con la máxima cautela hasta en tanto la investigación arqueológica cordobesa permita nuevos avances.

En el sepulcretum fueron distinguidas varias fases: Las tumbas más antiguas serían la 14 y la 27, con una cronología próxima al cambio de Era (López Jiménez 2006; vid. nota 2). La localización de la primera, exactamente a 12 pies de la fachada septentrional de los recintos, podría venir a confirmar la anchura de la vía funeraria, cuyas características estructurales no fueron registradas. A finales del siglo I a. C., o quizá ya en la primera mitad del s. I d. C., habría tenido lugar la parcelación, fijación y posible construcción de los primeros acotados; en un tercer momento, de cronología indeterminada pero centrado aún en el siglo I d. C., los recintos ya existentes serían reutilizados para nuevos enterramientos de cremación y de inhumación que afectaron a tumbas previas provocando superposiciones, y se habría construido alguno nuevo, como el no 8 -¿quizás también los otros de sillería...?-. En la segunda mitad del siglo I, o quizá primeros años del siglo II d. C., quedaría amortizada de manera definitiva la vieja vía funeraria; $y$, por fin, sobre todo ello se acabó disponiendo una gran estructura tardoantigua con técnica edilicia similar al opus africanum que aprovechó viejos cipos funerarios, a la que ha sido atribuido un carácter defensivo.

Analizo a continuación los recintos que han podido ser individualizados ${ }^{4}$ :

- Recinto i: Finaliza la serie -que pudo continuar en esa misma dirección- por el este, contiguo al Recinto 2, con el que solo comparte cimentación en su fachada septentrional, de 3,56 m de largo según las indicaciones del excavador. La misma fábrica, siempre de mampuesto y bolos de mediano y pequeño tamaño trabados con arcilla, se usó en su cierre meridional. Fue un locus cuadrado, de $12 \times 12$ pies. Adosadas a su muro norte se recuperaron, en dos filas superpuestas, 16 ánforas de tipologías variadas y fechas comprendidas entre los siglos II a. C. y II d. C., que debieron acoger enterramientos infantiles de inhumación, no conservados (López Jiménez 2010: 317). La práctica de buscar para las deposiciones funerarias el "abrigo" de los muros o las lindes, especialmente en los ángulos, es bastante habitual en los recintos cordubenses mejor excavados, caso por ejemplo de Llanos del Pretorio, y ha sido observado en el norte de

\footnotetext{
${ }^{4}$ Ignoro la numeración asignada a los recintos inicialmente por su excavador (López Jiménez 2010: 316 ss.), para seguir en parte la de A. Ruiz Osuna (2008: 163 ss.).
}

Italia incluso cuando los muros no existían (Tirelli 2005: 261; también, Cipriano 2005: 279 ss.; vid. infra).

- Recinto 2: Se dispone al oeste del anterior, con el que pudo haber compartido medianeras. Conservaba en fachada, quizá embutido en el muro de cierre, el terminus de su ángulo nordeste: un gran cipo en calcarenita de cabeza redondeada con indicatio pedaturae (Fig. 5): L.P XII, alusiva a un locus cuadrado de $3,67 \times 3,67 \mathrm{~m}$. Solo fue documentado su muro trasero, de mampuesto y bolos de pequeño y mediano tamaño, con posible alzado de tapial y baja altura, que englobaba en su esquina suroriental otro hito, en este caso anepígrafo, conforme a la costumbre de reservar los cipos con epigrafía a fachada o a una primera señalización que perdería sentido si el recinto se construía finalmente de obra (vid. infra). En su interior se recuperaron los enterramientos 34, 35, 37, 41 y 42; el segundo de ellos de inhumación en fosa simple bajo cubierta de tegulae, perteneciente tal vez a la segunda fase de la necrópolis, y las otras cuatro cremaciones, presuntamente de carácter primario. Los supuestos busta fueron cubiertos mediante tegulae, y varios de ellos contenían ajuar, en el que predominan la terra sigillata precoz de tipo Peñaflor, los ungüentarios de barro y de vidrio, las lucernas de venera, y alguna moneda. También se recuperaron grandes fragmentos quemados de la madera utilizada en las piras.

Los Enterramientos 41 y 42 utilizaron sendas urnas cerámicas con decoración pintada a bandas dispuestas sobre el pavimento; la primera de ella abrigada por una estructura de mampuestos de calcarenita, y la segunda aislada en uno de sus ángulos. Podrían haber contenido los restos de las Tumbas 34 y 37, que de ser así habrían servido de ustrina, lo que reduciría el número de enterramientos a dos cremaciones y una inhumación. Todo ello dibuja un panorama prácticamente gemelo al documentado en Llanos del Pretorio y La Constancia.

- Recinto 3: Perfectamente enrasado con la línea de fachada principal del sepulcretum, contaba con cimientos de mampuesto y bolos trabados con arcilla, y al menos a la cota conservada-fue uno de los pocos que pudo ser excavado en su totalidad- no mostraba traza alguna de puerta. Medía 4,30 × 3,62 m por el exterior, lo que equivale a 15 pies in fronte $\times 12$ pies in agro. Junto al Recinto 4 rompía, pues, el módulo base de la batería principal de acotados. No proporcionó enterramientos.

- Recinto 4: De 15 pies in fronte por 12 in agro, como el anterior, conservaba su fachada septentrional construida en sillería: dos grandes bloques dispuestos a soga y uno central a tizón, a la manera de clave o cipo terminal de carácter anepígrafo, conforme a una técnica que he podido observar también en el Recinto 


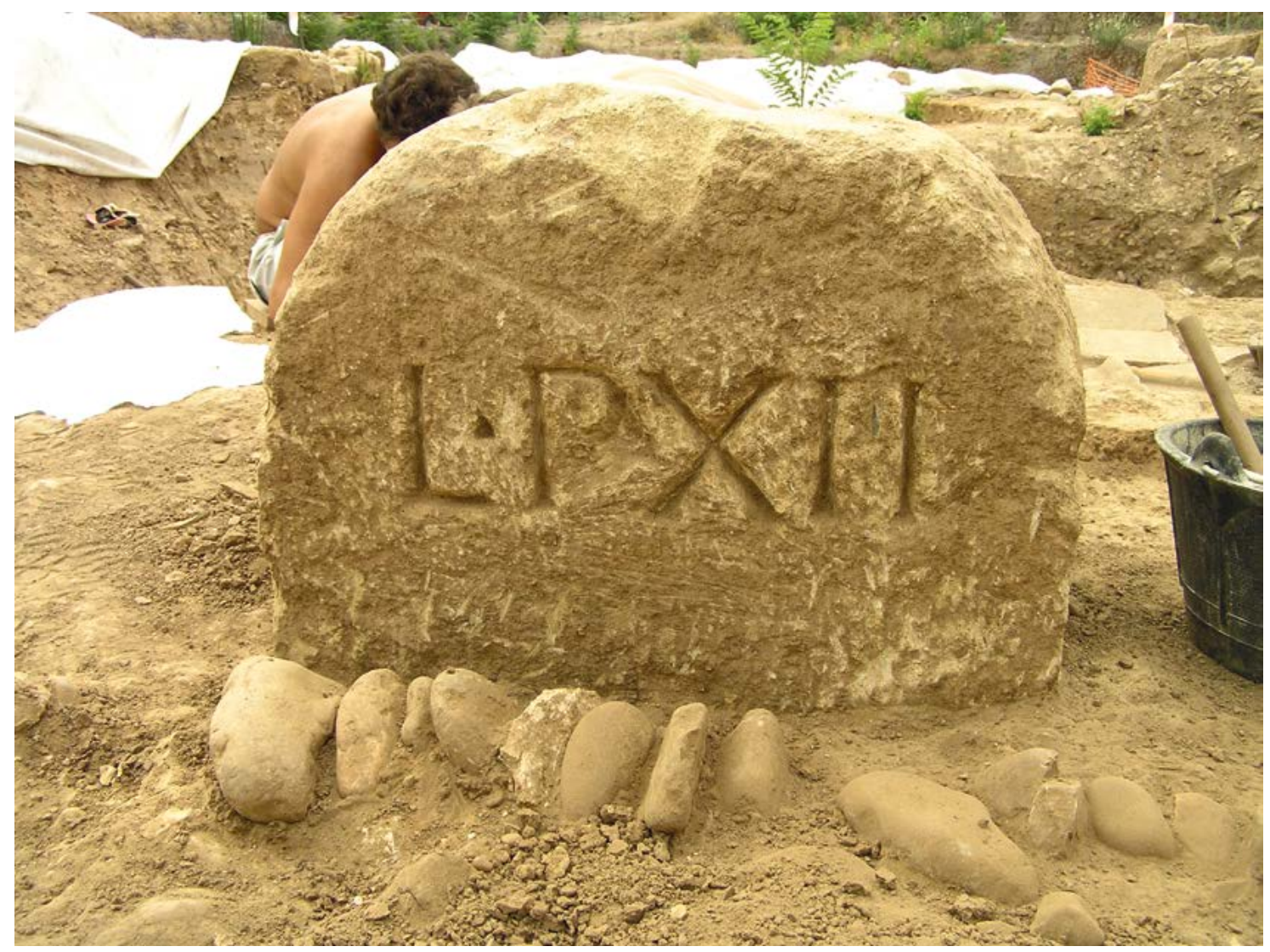

Figura 5. Avenida de las Ollerías. Cipo con mensurae sepulcri dispuesto en fachada del Recinto 2 (fotografía A. López Jiménez).

4 de Avenida del Corregidor, fechado a mediados del siglo I d. C. (Vaquerizo e. p.), lo que podría remitir a un mismo taller o maestranza. En el lado occidental, un sillar dispuesto en sentido norte-sur parece confirmar idéntica fábrica para esa medianera, mientras en el oriental los sillares se adosan con claridad al cierre del Recinto 5. Uno de los sillares conservaba como marca de taller una $F$ invertida, que en otros contextos cordubenses ha sido fechada entre el siglo I a. C. y el siglo I d. C. (Ruiz Osuna 2008: 167).

- Recinto 5: Conservaba únicamente los dos cipos angulares de su fachada septentrional, que delimitaban una superficie de $12 \times 12$ pies. Todo el conjunto se vio muy afectado por la ocupación de época islámica. No proporcionó enterramientos 5 .

RECiNTo 6: Su planta, cuadrada $(3,60 \times 3,60 \mathrm{~m})$, quedaba fijada en fachada por dos grandes sillares de calcarenita usados a la manera de cipos $-74 \times 74 \mathrm{~cm}$

\footnotetext{
${ }^{5}$ Sobre la ausencia de enterramientos en algunos recintos, vid. infra.
}

el oriental; $77 \times 70$ el occidental (López Jiménez 2010: 316)-, con el titulus en su cara frontal: L.P. XII/V.I.C. (Fig. 6, A y B). El espacio entre ellos habría quedado cerrado con mampuesto y cantos, trabados supuestamente por opus caementicium. Esto hace difícil afirmar que pudiera corresponder a una puerta, aun cuando no descarto en absoluto esa posibilidad si identificamos lo conservado como parte de los cimientos. Pudo estar pavimentado mediante una capa de picadura de sillar, y no proporcionó enterramientos, salvo el de un galgo en la zona sur (Ruiz Osuna 2008: 170). Enterramientos de perros aparecen también en Llanos del Pretorio (sobre el tema, vid. por ejemplo Bodson 2001; De Grossi 2001; Bennet y Timm 2016, o Martínez Sánchez 2020 y e. p., con bibliografía anterior).

En un análisis simplista, las abreviaturas $V \cdot I \cdot C$ podrían corresponder a la fórmula onomástica abreviada, tal como se documenta en la Cisalpina -caso de Aquileia o Altinum-, donde en ocasiones los termi$n i$ así señalizados, sobre soportes y con formatos va- 

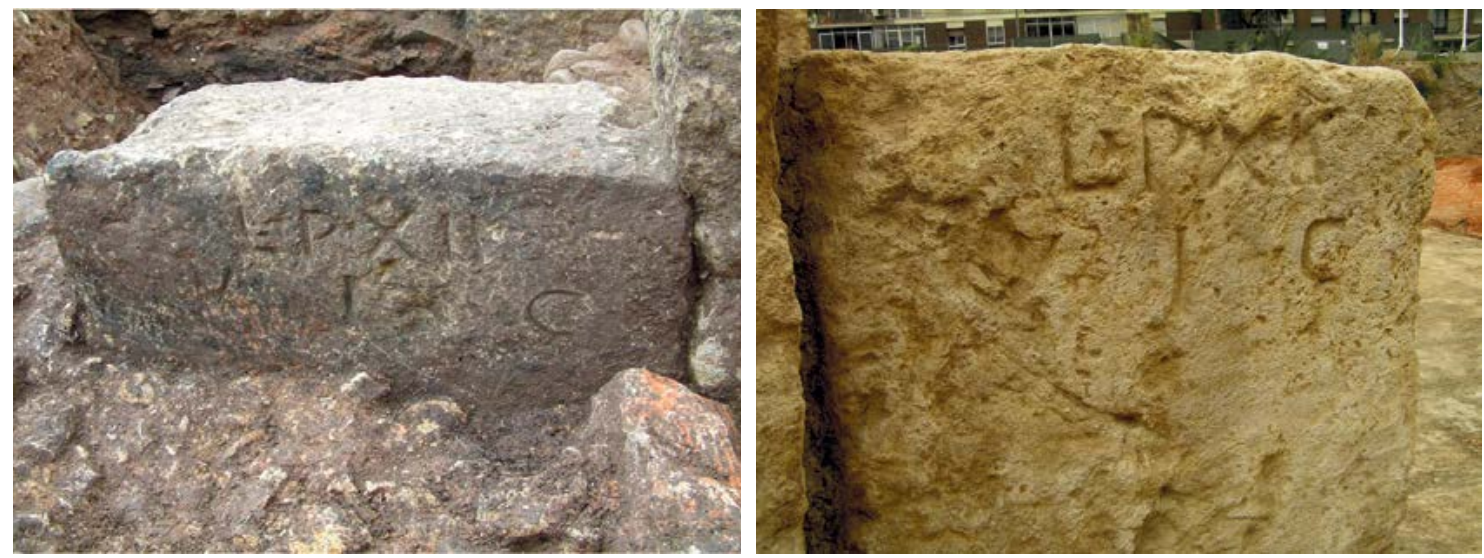

Figura 6. Avenida de las Ollerías. Recinto 6. A y B) Tituli con mensurae sepulcri y posible referencia catastral (fotografía A. López Jiménez).

riables pero que difícilmente podrían acoger algo más que las iniciales, remiten a otra inscripción principal o titulus maior con los datos en detalle del propietario (Zaccaria 2005: 201, figs. 8, 10 u 11; Cresci Marrone 2005: 307 ss.). Hay decenas de estelas que siguen este patrón, lo que implica que se trataba de un uso asumido y comprensible para todos al menos en aquella zona (Vaquerizo 2010: 110 ss.). Sin embargo, para Sergio García-Dils, a quien agradezco sus indicaciones sobre este tema, $V \cdot I \cdot C$ es más que dudoso como tria nomina, tampoco constatados por el momento con esta morfología sobre otros cipos con pedatura en Córdoba; y al tratarse de recintos en principio colectivos -0 cuando menos familiares- lo usual es que se hubiera indicado el nomen, la gens del propietario a texto completo. Por otra parte, el único praenomen que comienza con $V$, Vibius, es raro como tal, y suele ir desarrollado -verbigracia: Vibi f(ilius), o Vib(i) f(ilius) - a fin de hacerlo inteligible, algo que no habría sido necesario con un $Q$ (uintus) o un $L$ (ucius), por ejemplo; y no conocemos paralelos para Vibius Iunius o Iulius, con Vibius como praenomen (lo normal es que si el nomen fuera más raro que Iunius o Iulius se hubiera indicado). Por fin, los Vibios que aparecen en Córdoba y Baetica-también fuera- son siempre nomina.

Parece más lógico, en consecuencia, que se tratara de una indicación viaria a la manera de las utilizadas en la agrimensura; punto de vista desde el que cabrían diversas opciones. En primer lugar, la $C$ podría hacer referencia a $C($ orduba) o a la $c$ (olonia), en una alusión clara para todos. Tanto es así, que si la fórmula fuese en la misma línea de la indicatio pedaturae se habría podido confundir con una abreviatura de tipo administrativo. Como no es el caso, la hipótesis más plausible sería que estuviera invocando la vía junto a la que se dispone la tumba, como se constata en algunos epígrafes de dentro y fuera de la Bética. En tal caso, la lectura podría ser la siguiente: $V($ ia $)$ i(n) C(ordubam), o $V($ ia $) i(n)$ c(oloniam), usando como referencia para el locus la carretera "hacia Córdoba" o "hacia la colonia". Con todo, es importante señalar que en los tituli sepulcrales las menciones a las vías no suelen aparecer abreviadas -vid., por ejemplo, Cástulo, CIL II 3282; Roma, CIL I 3021; Collefracido (Samnium), CIL IX 4348, o Brixia, CIL V 4783, entre otros-, por lo que en el mejor de los casos se trataría de una excepción.

Si aceptamos por otra parte la proximidad al sepulcretum del supuesto ramal de la via Augusta defendido tradicionalmente por la historiografía cordobesa, que de haber existido se convertiría al entrar en la ciudad por la actual Puerta de Osario en el cardo máximo, es muy posible que la solución haya que buscarla en las fórmulas utilizadas para las centuriaciones -por ejemplo, d(extra) d(ecumanum) / s(inistra) d(ecumanum); $u$ (ltra) $k$ (ardinem) / c(itra) $k$ (ardinem) $-^{6}$, de forma que V.I.C. podría leerse como via I citra (la calle $\mathrm{n}^{\circ} 1$ a este lado -de la calle principal-), o Vltra I Cardinem, también posible con la grafía VKI. Esta hipótesis, con refrendo en ciudades como Aquileia o Altinum, donde recintos y acotados llegaron en algún caso a adoptar formas poligonales trazadas a partir de referencias catastrales (Zaccaria 2005: 200 y 203; Buonopane y Mazzer 2005: 329), se habría visto reforzada por la existencia de otras vías secundarias en el sepulcretum, no documentadas sin embargo por la arqueología.

- Recinto 7: Contiguo por el lado occidental al Recinto 6, era de nuevo un locus de $12 \times 12$ pies seña-

\footnotetext{
${ }^{6}$ Un caso bastante expresivo en CIL VI 29480. También, por ejemplo, en $A E 2005,577$ y 598, ambas de Altinum, o CIL V 1472 y 1477 , de Aquileia.
} 
lizado por sendos cipos en fachada, anepígrafos ambos. Parece confirmar que la serie continuaba de manera sistemática hacia el oeste conforme al módulo predominante, si bien caben otras opciones: tal vez se interrumpió aquí, o las superficies cambiaron. En este sentido, las deficiencias de la documentación manejada, así como la acción predadora de la ocupación islámica, impiden llegar más allá.

- Recinto 8: No pudo ser documentado en su totalidad por quedar embutido en el perfil occidental del corte, pero sus muros estaban construidos en sillería de gran formato $(1,40 \times 0,54 \times 0,48 \mathrm{~m})$; y en este sentido, a pesar de las dificultades para interpretar estratigráficamente los diversos sectores excavados, parece haber razones arqueológicas suficientes para confirmar que en la Córdoba romana el uso de la sillería fue posterior al del tapial y el mampuesto, aun cuando se usara sobre cimentaciones de cantos de río. Solo se exhumaron 9,2 $\mathrm{m}$ de longitud de su cierre oriental, y 2,2 m del meridional, lo que apunta a un acotado de dimensiones bastante superiores a las del resto. El primero habría bloqueado por completo la vía funeraria si hubiera existido a la vez que ella; de ahí que me decante efectivamente por encuadrar a esta estructura en la tercera fase de la necrópolis. El hecho de que acabara amortizándola se convierte, a mi entender, en prueba fidedigna del valor funerario -y no de tránsito sensu stricto- de aquella. Finalmente, la localización en el desmonte del sector de un gran fragmento de pulvinus tallado en arenisca local y el titulus sepulcralis de una flaminica, ambos de la primera mitad del siglo I d. C., ha servido para sugerir que pudiera haber acogido en su interior un monumento funerario de tipo altar (Ruiz Osuna 2008: 170 ss.), si bien las fechas parecen algo forzadas.

- Recinto 9: Se ubicaba algunos metros al sur de la línea principal de acotados, y no pudo ser excavado completo por subsumirse hacia el este bajo la zona de arrabal islámico. Su orientación coincide en líneas generales con la de aquellos, pero su mal estado de conservación y la imposibilidad de fijar sus límites con precisión hacen complicado intentar proyectar a esta zona las modulaciones constatadas más al norte.

Tres filas de recintos han sido documentadas en la necrópolis de la Strada di Raccordo de Altinum (Cipriano 2005: 278), y cinco en Aquileia (Reusser 1985: 130 ss., y 1987, 241 ss.), pruebas ambas de una lotización del espacio funerario bien sistematizada y quizás reglada. En Ollerías podría también haber sido parcelado inicialmente todo el sector con independencia de cómo acabaran disponiéndose los respectivos loci, o de que estos terminaran ocupándose en su totalidad; pero no conocer siquiera el trazado exacto de la via Augusta limita sobremanera la comprensión de la topografía.
Se trata, en definitiva, de un sector funerario en el que sorprende la complejidad de la topografía, la monumentalidad de sus expresiones arquitectónicas, su gran diacronía, y que las estructuras funerarias ofrezcan tanta uniformidad en sus superficies. De hecho, solo los Recintos 3 y 4, con medidas de 15 pies in fronte por 12 pies in agro, no indicadas sobre los cipos conservados, parecen romper la norma general de 12 $\times 12$ pies común para el resto en la primera fase, estructurada en cualquier caso conforme a un módulo único in agro de 12 pies. También sus fachadas muestran una cierta similitud, aunque no son idénticas, ni mucho menos, lo que sugiere un cierto afán por individualizarlas. Todo ello refleja una complejidad en la ocupación funeraria de la zona -ritual, espacial y cronológica-, que la intervención arqueológica no llegó a clarificar en su plena dimensión, y que hoy solo podemos intuir.

Los recintos de Ollerías emplean en su mayor parte como sistemas constructivos alzados de opus incertum dispuesto entre los cipos, que actúan a modo de tirantas conformando una suerte de opus africanum cimentado sin excepción sobre una base de piedra o cantos de ríos. Al menos dos de ellos fueron construidos de sillería en una fase posterior, visto que el Recinto 8 cerraba la vía funeraria por el oeste. Los mejor conservados dispusieron muy probablemente de puerta de acceso, que monumentalizaban los propios cipos delimitadores y abría a la calle. Componían así una fachada continua similar a las también detectadas en la mayor parte de los sepulcreta reseñados al inicio de este trabajo, y confirman la existencia de grandes programas edilicios suburbanos de componente estrictamente funerario.

En un primer momento los acotados habrían acogido enterramientos de cremación, casi siempre primaria -en algunos casos las piras se dispusieron en el interior de los mismos-, pero no faltan las inhumaciones, de cronología más tardía o indeterminada. La mayor parte de ellas aparecieron, no obstante, fuera de los recintos, cuya altura, cuando contaron con muros perimetrales, ignoramos sin excepción. No parece haber sido mucha en cualquier caso, dada la rapidez con que fueron amortizados y sus superficies utilizadas para nuevos enterramientos.

\section{LLANOS DEL PRETORIO}

El sector del sepulcretum intervenido -avances en García-Dils y Rubio 2018; Vaquerizo et alii 2019 y e. p.- se estructuró a partir de, al menos, dos vías 
de uso específicamente cementerial con orientación este-oeste (Fig. 7). Los recintos de la serie septentrional compartían linde trasera con una tercera línea de acotados bien documentada en la esquina nororiental y en el perfil norte del solar (así se comprueba en los denominados $\mathrm{O}$ y $\mathrm{P}$ ), que abrirían a una posible segunda vía de características similares a la excavada.

La intervención arqueológica recuperó un tramo de $28 \mathrm{~m}$, con firme de picadura de sillar y 2,40 m de ancho (8 pies romanos), que debió discurrir perpendicular a las vías principales que salían de la ciudad en dirección norte. Daban fachada a ella sendas series de recintos no del todo simétricos ni tampoco iguales, lo que sugiere una dinámica más compleja y diacrónica de la que dejaría entrever una parcelación rigurosa y una construcción simultánea. Tal vez intervinieron en su trazado condicionantes de tipo orográfico, de propiedad de la tierra, o de sucesión cronológica. En realidad, lo normal fue que las necrópolis crecieran de manera desordenada, aun estando bajo el control de la curia (Campedelli 2005: 179).

El conjunto ha proporcionado 52 enterramientos de cremación, 13 inhumaciones perinatales y 2 deposiciones de cánidos. Un buen número de ollae ossuariae debieron ser depositadas directamente sobre el suelo y a la vista, como ha sido señalado en otros sepulcreta similares (Cipriano 2005: 280 ss.), lo que permite suponer que algunas, tal vez en contenedores de mayor calidad, pudieran haber desaparecido víctimas de las rapiñas o los procesos postdeposicionales. Esto explicaría también, por lo menos en parte, que ciertos recintos -no solo en Córdoba (Tirelli 2005: 259 ss.)-, aparezcan vacíos.

La línea de recintos meridional quedaba delimitada en su parte trasera por un muro de $0,70 \mathrm{~m}$ de ancho y una potencia conservada en algunos puntos de 1,31 $\mathrm{m}$, construido en mampostería combinada con algo de sillería. Dicho muro no sirvió de cierre a los recintos, sino que estos apoyaron su fachada trasera en él. Así se observa en el Recinto G. Ello no evitó que, particularmente en los loci no construidos, los enterramientos buscaran su "protección" (vid. supra), entre otras razones para liberar espacio en el que disponer las piras. En el relleno de su zanja de cimentación se recuperó una lucerna del tipo Loeschcke III, con decoración geométrica en el disco, dos piqueras y asa plástica, cuya producción comienza con Augusto y alcanza su mayor auge en la primera mitad del siglo I d. C. (Cipriano 2005: 278; Morillo 2015: 354 ss.); cronología que desde el punto de vista de los repertorios materiales predomina con claridad en el complejo y lo equi-

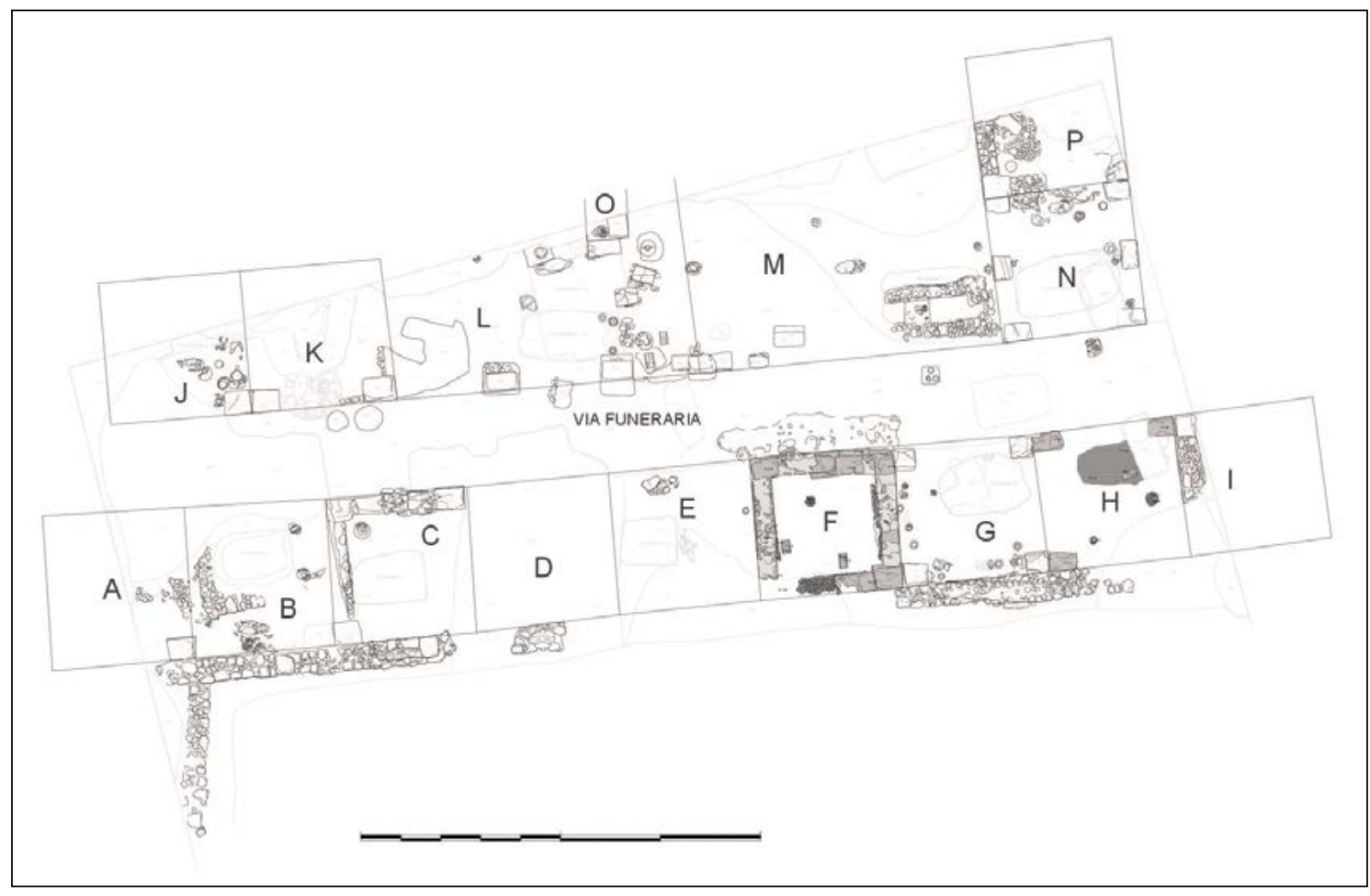

Figura 7. Llanos del Pretorio. Planta general del sector intervenido (cortesía M. Rubio Valverde). 
parara con otros conjuntos del norte de Italia (Cresci Marrone y Tirelli 2005).

A la vista de lo anterior, debió tratarse seguramente de un sector funerario cerrado. Promotores privados o públicos pudieron haber comprado un terreno, o derivado en este mismo sentido una finca, privada o pública, para después parcelarla en lotes y vender estos con fines cementeriales y tal vez carácter especulativo, dada la altísima demanda que debió existir de suelo funerario en Colonia Patricia desde principios del Imperio, sobre todo en un sector tan próximo a las murallas y a vías de tanta trascendencia y trasiego en los primeros siglos de la ocupación romana. El sepulcretum de Avda. de las Ollerías (López Jiménez 2006 -vid. nota 2-; Ruiz Osuna 2007b: 34 ss.; Vaquerizo y Sánchez 2008: 124 ss.) parece responder a una dinámica y cronología inicial similares y, sin embargo, se encuentra a una milla larga de la puerta septentrional de la urbe lo que, en cualquier caso, obliga a ser cautos al respecto. Fue una práctica que quizá utilizó la propia curia, reservándose espacio para la concesión de honores funerarios (Antico 1997: 214 ss.; Zaccaria 2005: 198; Melchor 2006a: 116 ss. y tabla final, en 137 ss.; Ruiz Osuna 2007a: 147; Vaquerizo 2010); y no hay que olvidar el papel que al respecto desempeñó el evergetismo: muy conocidos son los casos de Horatius Balbus en Sarsina (CIL XI, 6528; Cenerini 2005: 138 ss.), y de C. Veienus Trophimus en Tolentinum (ILS, 7847; Purcell 1987: 36 ss. n.8; Vaquerizo et alii 2019: 80).

En opinión de J.F. Rodríguez Neila (1991: 80), la regularidad de los acotados funerarios cordubenses podría tal vez "interpretarse como resultado de ordenanzas municipales concernientes a la distribución y medidas de los espacios de uso funerario y a su protección como loci religiosi"; entre otras razones porque para garantizar la sacralidad de un espacio era preciso definir, y a ser posible explicitar con toda claridad, sus confines (Sartori 2005: 165). No sería por tanto descabellado pensar que la aplicación de un módulo tan regular, repetitivo y posiblemente básico para la asignación de tales acotados pudiera haber venido ya establecida en el propio ordenamiento catastral de cada colonia; idea válida quizás para los recintos que han conservado testimonio epigráfico de las mensurae sepulcri, pero más difícil de encajar en los que rompen la norma. Por el momento, de hecho, no contamos con información alguna sobre la existencia de una normativa municipal en Córdoba que regulara este tipo de actividades; ni tampoco hemos logrado explicar de forma convincente el corto recorrido cronológico de tal práctica. De ahí que convenga además tener en cuenta otros factores, como la tradición del lugar de origen y las modas. Es importante recordar al respecto que el carácter marcadamente modular, racionalis- ta y funcional de la topografía inicial del sepulcretum localizado en Llanos del Pretorio no se mantuvo inflexible, y tras una primera línea de recintos bastante uniformes, la segunda y tercera observan dinámicas algo diferentes, no determinadas sin embargo por la excavación en sus detalles ni en su cronología últimos.

La mayor parte de los recintos documentados (A, B, C, F, G, H, I, J, K y P) eran de planta cuadrangular, con una superficie aproximada de $3,55 \mathrm{~m}$ por $3,55 \mathrm{~m}$ $-12 \times 12$ pies romanos-. Utilizaron como señalizadores de su respectivo locus un número no siempre determinado -mayoritariamente, cuatro- de cipos de piedra calcarenita con morfología desigual, dispuestos de forma vertical en cada una de sus esquinas. Hablo de cipos por tratarse de bloques paralelepípedos de sección cuadrada o tendencia rectangular, más funcionales que bellos o con pretensión de serlo. Este es el nombre utilizado -raramente, en cualquier caso- por la epigrafía tardorrepublicana y protoimperial en Roma, mientras en época imperial convive con el de termini, más habitual en propiedades públicas o privadas de mayor tamaño (Gregori 2005: 83 ss.; Zaccaria 2005: 200). Los que sirvieron en el Pretorio como soportes para las mensurae sepulcri tienen cabecera redondeada; también los que se disponen en fachada de los Recintos L y M, incluido el que acogía en su tercio superior el titulus sepulcralis de Bassa, dedicado por I. Iuventius Amarantus.

Los Recintos F y G conservaban en sus muros traseros, dando vista al interior del locus, no a fachada, sendos cipos con el titulus L(ocus) P(edum) XII, indicatio pedaturae que corrobora la realidad arqueológica y alude al módulo mayoritario en el sepulcretum y en Córdoba (Fig. 8). Vienen a sumarse a los otros 10 termini con mensurae sepulcri ya conocidos en Córdoba; con un predominio absoluto en ellos -en torno al $80 \%$ - del módulo de $12 \times 12$ pies (Vaquerizo y Sánchez 2008: 104, 2009).

En el Recinto F el cipo con mensurae sepulcri quedó, además, embutido en el muro, y seguramente no visible. Esta circunstancia pudo tener que ver con el carácter "secundario" que la pedatura desempeña con relación a la epigrafía funeraria sensu stricto cuando convive con ella (Sartori 2005: 165). Tal vez, tras ser repartidos y ocupados los diferentes lotes de tierra, la función principal de la indicatio era asumida por la propia materialidad de los termini, de los muros de cierre cuando se construyeron, o de cualquier otra referencia. Lo normal, de hecho, cuando las medidas del locus aparecen solo en uno o dos cipos, fue que estos se dispusieran en fachada para que pudieran ser vistos (Cresci Marrone 2005: 307 ss.).

Todo ello parece confirmar la idea apuntada más arriba: el propietario o promotor -público o privado, 


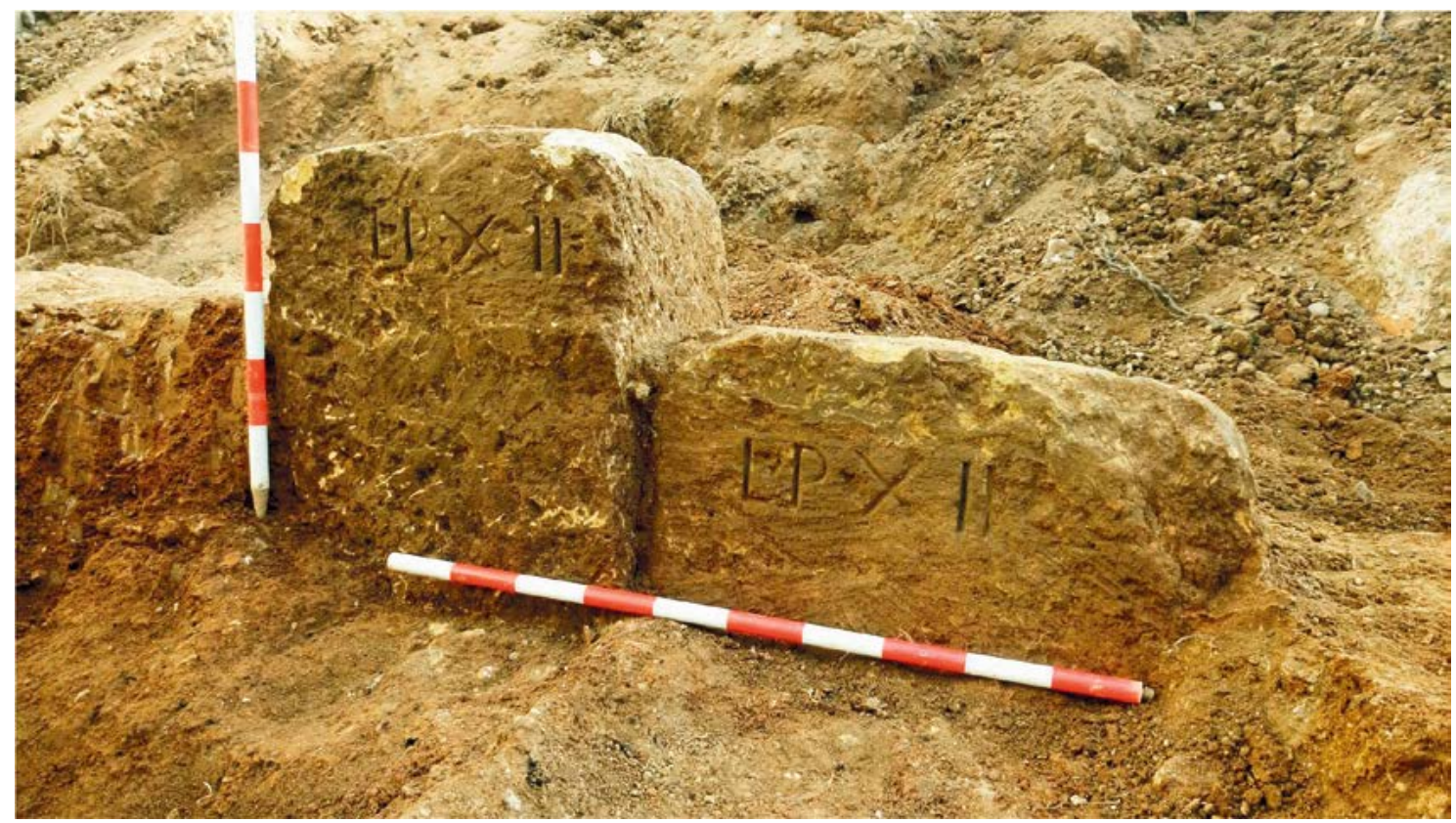

Figura 8. Llanos del Pretorio. Recintos F y G. Cipos con mensurae sepulcri (fotografía M. Rubio Valverde).

eso habría que determinarlo ${ }^{7}$ - lotizaba el terreno y lo vendía modulado (Liguori 2005: 157), sin que por el momento sea posible concretar si la iniciativa de señalizarlo -terminare, denominan tal acción algunos epígrafes de Altinum, con un verbo propio del lenguaje técnico jurídico del que deriva el concepto de terminus (Buonopane y Mazzer 2005: 328)- le correspondía a él, al comitente, o a cualquiera de ellos según el caso $^{8}$, mientras que el uso de una u otra fórmula pudo ser decidido por la oficina (Campedelli 2005: 175). De ahí quizás, más allá de que incorporaran o no epigrafía, la diversidad observada desde el punto de vista estructural: recintos con seis, cinco, cuatro o dos cipos, incluso sin ellos ( $v . g$. Recinto E); aunque es difícil afirmarlo de forma categórica debido a la acción en la estratigrafía de procesos postdeposicionales por regla general muy traumáticos que han desconfigurado en muchos casos el paisaje funerario inicial, o al uso para la señalización de materiales no

\footnotetext{
${ }^{7}$ En Altinum la reiteración de módulos obedece a "un programma preliminare, probabilmente pubblico, di pianificazione degli spazi necropolari, articolato in lotti di diferente entità" (Tirelli 2005: 254).

${ }^{8}$ De nuevo en Altinum, la disposición sobre el terreno de dos estelas gemelas anepígrafas ha sido interpretada como "la predisposizione di un recinto, già fornito di appositi termini sepulcri, ma in attesa di un potenziale acquirente" (Cresci Marrone 2005: 315)
}

duraderos y más difíciles de observar arqueológicamente (vid. infra).

Tal variedad se observa también en Roma, donde la propia epigrafía no deja lugar a dudas sobre el uso múltiple de este tipo de señalizadores al aludir a ellos en plural, si bien la realidad arqueológica resulta esquiva al respecto. De un catálogo en torno a las mil inscripciones, poco más de diez casos corresponden a combinaciones de cuatro cipos o estelas, una veintena larga a tres, y en torno al centenar y medio a dos, lo que ha llevado a suponer que el método habitual de señalización se sirviera de cipos con tituli inscritos solo en fachada, reservando para la parte trasera métodos alternativos más baratos (Gregori 2005: 84). Esta realidad parece contradecir, o por lo menos matizar, la variada casuística detectada día a día en Córdoba, donde es cierto que la epigrafía grabada en piedra no resulta demasiado abundante, pero sí los cipos pétreos -la perdurabilidad como garantía de memoria (Sartori 2005: 165)-, anepígrafos hoy pero quizá no en su momento, gracias al uso de tituli picti.

Con la única excepción de los Recintos L y M, que comparten terminus (en el Recinto B solo se constató el cipo de su ángulo suroriental), en Llanos del Pretorio la delimitación entre acotados contiguos se hizo mediante cipos gemelos. Dado que el proceso de excavación no detectó huella arqueológica alguna de los sistemas de cierre en los no rodeados por muros de obra, debemos suponer en principio que los bloques 
de las esquinas bastaron para señalizar los respectivos loci, por lo que el problema en estos casos sería el de garantizar su protección.

Como en otros lugares del Imperio, muchos de los acotados funerarios existentes en la ciudad pudieron haber sido señalizados también mediante altares, columnas, verjas de hierro, material perecedero -vallas, vegetación, cuerdas o cipos de madera (Verzár-Bass 2005; Tirelli 2005, 255 ss., Figs. 12 y 13; Cafiero 2005), de los que en Córdoba no tenemos constancia arqueológica-, accidentes geográficos y físicos, o referencias a edificios, acueductos, vías y cursos de agua cercanos. En efecto, además de los cipos, las fuentes epigráficas citan como elementos delimitadores muretes y/o balaustradas-agelli, maceria (recuérdese por ejemplo la representada en el famoso monumento de los Haterii, en Roma; Sinn y Freyberger 1991: 53, tav. XIV, 2)-, cercados o vallas - parietes-, vías y corrientes de agua -rivi, undae-, e incluso zanjas -fossae(Rodríguez Neila 1991: 69 ss.; Hesberg 2005: 63 ss.). Son aspectos que dibujan una topografía cementerial mucho más compleja, rica y sistematizada de la que hasta ahora ha logrado perfilar la arqueología, que deberá extremar el rigor metodológico para ayudar en la recreación de su paisaje funerario.

Hubo, no obstante, en Llanos del Pretorio varios recintos que, a la manera de otros muchos ejemplos repartidos por las diversas áreas funerarias patricienses, cerraron el espacio mediante muros de fábrica y monumentalizaron sus entradas; algo que, más allá de opción personal o familiar, dejaba por un lado constancia de mayor poder adquisitivo, y por otro singularizaba las tumbas, al tiempo que las protegía. Fue bastante común que los recintos presentaran sus muros ciegos, incluso cuando alcanzaban alturas superiores a las de un hombre medio. Esto obligaba a saltarlos cada vez que se debía realizar algún enterramiento en su interior (vid. al respecto Vaquerizo 2002) y a celebrar fuera de ellos la mayor parte del ritual funerario y las ceremonias conmemorativas (Hesberg 2005: 68).

Hablo de los recintos C, F, I ${ }^{9}$, K, y quizás L, M y $\mathrm{P}$, si bien solo nos ha llegado completo el segundo de ellos (F), que efectivamente se rodeó de muros de mampostería, con una entrada en fachada flanqueada por dos cipos de calcarenita -uno de los cuales marcaba el ángulo nororiental del acotado funerario-, escalón de acceso por hallarse el nivel de uso más bajo

${ }^{9}$ Del Recinto I solo se pudo documentar su cipo noroccidental y parte del muro de mampostería - de grosor considerable y revestimiento de mortero de cal- que lo cerraba por el oeste, aun cuando cabe deducir que siguiera el módulo de $12 \times 12$ pies imperante en toda esa línea de acotados. El resto del espacio funerario se introduce en el perfil este. No proporcionó ningún enterramiento. que la calle, y un cuidado remate en el revestimiento interior de los muros mediante incisiones en el mortero que intentaban imitar un despiece de sillarejo (Fig. 9). Tanto este escalón como el que daba entrada al Recinto C -ambos de calcarenita- contaban con sendas quicialeras, prueba irrefutable de la existencia de puertas -recintos con escalones y quicialeras en las entradas han sido observados también en Camino Viejo de Almodóvar (Ruiz Osuna 2005)-. En los otros cinco no se constataron huellas de vanos, y el resto podrían haber quedado abiertos, marcados quizás con vegetación, madera o cuerda. Son matices que separan a los recintos cordobeses globalmente entendidos del modelo cisalpino sensu stricto (Tirelli 2005), en beneficio de una posible pluralidad de influencias en cuanto a los modelos que llegan y se adoptan.

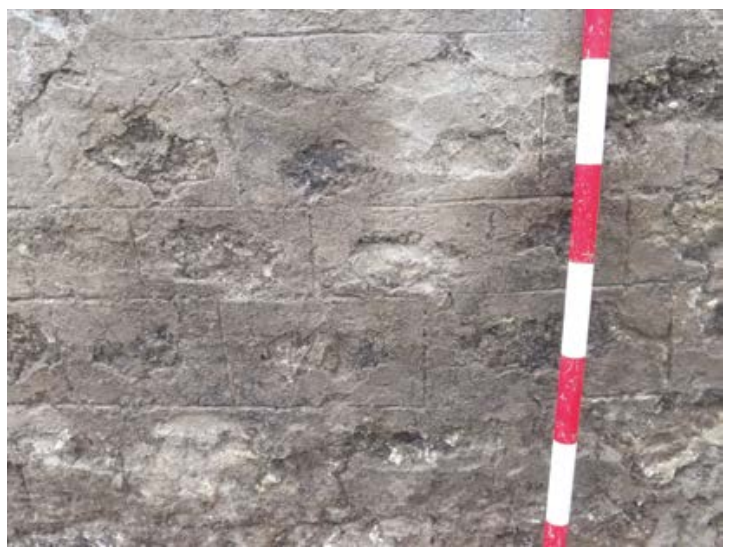

Figura 9. Llanos del Pretorio. Recinto F. Detalle del enfoscado interior de los muros con despiece de sillería simulado (fotografía M. Rubio Valverde).

Parecen romper la dinámica general los Recintos E, L, M y O, cuya organización, en principio, no sigue el módulo mayoritario. En el primer caso, dos fosas de épocas califal y contemporánea deformaron por completo su aspecto original. Con todo, la distancia entre $\mathrm{C}$ y $\mathrm{F}$ es de 7,10 m, el tamaño que ocuparían dos acotados de $12 \times 12$ pies; de ahí que hayamos supuesto la existencia entre ellos de D y E, aun cuando no cabe descartar que un mismo propietario pudiera haber adquirido dos lotes. Más complicado es el caso de los Recintos L y M, que según todos los indicios fueron concebidos conforme a un esquema diferente: en lugar de los bloques de ángulo habituales en el resto de los casos, presentan una fachada salpicada por cipos de cabecera redondeada unidos por muretes de tapial que han conservado parte de su revestimiento original y podrían haber quedado separados por un alzado de 
mampostería con apenas una hilada, documentado en su arranque junto al cipo que ambos comparten. $\mathrm{Si}$ bien con una potencia mucho menor, el pavimento de picadura de sillar utilizado en la vía funeraria se prolonga en el espacio ocupado por ellos, roto por las zanjas de cimentación de los cipos de fachada, las fosas de algunos enterramientos y de uno de los ustrina. Pudo, pues, haberse tratado inicialmente de un espacio abierto o de tránsito hacia la segunda vía situada más al norte -¿quizá posterior?-, de reserva, o destinado a horti, después estructurado en dos acotados de $12 \times 12$ pies (J y K) y dos más (L y M) de dimensiones inusuales pero con idénticas medidas in fronte (51,75 pies) e in agro (12 pies).

Espacios intermedios similares han sido detectados como ya vimos en otros sepulcreta de la ciudad, caso de La Constancia (Vaquerizo et alii 2005: 66), y también en necrópolis emblemáticas del Imperio, como Ostia Antica o Isola Sacra (Calza 1940; Heinzelmann 2000; Taglietti 2001; Baldasarre 2002); y aboga en beneficio de nuestra hipótesis que ambos recintos presenten enterramientos con una diacronía bastante más acusada que el resto (Vaquerizo et alii 2019). No lo olvidemos: este tipo de necrópolis eran espacios vivos, en permanente conformación y transformación.

Confirman la existencia de una tercera línea de recintos -imposible determinar hasta qué punto completada en el momento de la colmatación del sepulcretum-, contigua a la segunda por sus medianeras traseras y abierta en principio a una segunda vía, los recintos $\mathrm{O}$ y $\mathrm{P}$. El único cipo conservado del Recinto O correspondía probablemente a su esquina suroriental, cuya protección buscaban de nuevo los enterramientos. Por su parte el Recinto P, que mantenía el módulo de $12 \times 12$ pies y se adosaba al $\mathrm{N}$ por el norte, debió quedar delimitado por cuatro cipos en sus esquinas (conservaba los dos meridionales), y fue delimitado mediante estructuras de mampostería, bien documentadas en sus lados meridional y occidental.

Finalmente, la práctica totalidad de los recintos de Llanos del Pretorio contó en su interior con uno o varios ustrina por lo general en fosa simple, aunque no faltan algunos delimitados por muros de obra, y casi siempre con huellas claras de haber acogido una o varias cremaciones (Ruiz Osuna e. p.); algo no habitual en otras necrópolis (Cipriano 2005: 279). Destacan en este sentido el Recinto L, con dos quemaderos, el primero de ellos construido ya sobre tres enterramientos anteriores, y el Recinto E, con tres ustrina superpuestos.

Nos hallamos, en síntesis, ante un sector funerario de marcada planificación, predominio del módulo de $12 \times 12$ pies, y compleja topografía, estructurada en torno a dos o más diverticula trazados ex profeso con fines funerarios. Deja constancia así, una vez más, de la densidad y riqueza que llegó a alcanzar el paisaje funerario romano de los primeros siglos imperiales en la capital de Baetica, y de su fuerte impronta itálica, por más que muchos de los enterramientos se sirvieran para acoger los restos óseos de urnas cerámicas de supuesta tradición indígena (García Matamala 2002 y 2002-2003; García Matamala y Liébana 2006; Jiménez Díez 2008), que constituyen una de las líneas de trabajo prioritarias para los próximos años (Fig. 10). En efecto, su categorización como tales pudo tener sentido mientras aparecieron de manera ocasional. A día de hoy, sin embargo, sabemos que fueron el tipo de olla ossuaria predominante entre finales del siglo I a. C. y mediados del siglo I d. C., no solo en Córdoba (vid. por ejemplo, para el caso de Segobriga, Cebrián y Hortelano 2016: 38 ss., fig. 33; también, la dinámica detectada recientemente en Baelo Claudia y la Silla del Papa; Moret et alii 2017: 61 ss.), lo que añade al problema nuevos matices. Su fabricación parece claramente local, y no cabe descartar cierto ejercicio de hibridismo, pero es posible también que nos encontremos ante productos de tradición itálica o mediterránea (nunca revisados desde este punto de vista), en boga durante la etapa augustea.

\section{PARCELACIÓN FUNERARIA Y MENSURAE SEPULCRI: ¿PRAGMATISMO O MODA...?}

\section{I. LA VOZ DE LA ARQUEOLOGÍA}

La arqueología nos ha permitido estos últimos años detectar en las áreas funerarias romanas de Córdoba varios sectores específicamente acondicionados para fines cementeriales, lotizados por iniciativa pública o privada y vendidos después a particulares, que señalizaron sus loci con cipos de piedra -quizás también algunos con madera y tituli picti, u otros materiales orgánicos-, con o sin indicatio pedaturae, y en ocasiones los rodearon de muros, por lo general de no demasiada altura y a cielo abierto, con o sin puertas (vid. infra), a fin de que, como era habitual y conveniente, quedara constancia de su integridad en ámbito privado y también público. Tanto los cipos recuperados en Avda. de las Ollerías como en Llanos del Pretorio, tallados sin excepción en areniscas locales, fueron extraídos tras la excavación, y en su mayor parte desechados como escombros. Sobre los primeros no tengo información fidedigna, pero de los segundos fueron tomadas escrupulosamente sus medidas totales (Fig. 11), que oscilan entre el 1,70 $\mathrm{m}$ de uno de los 

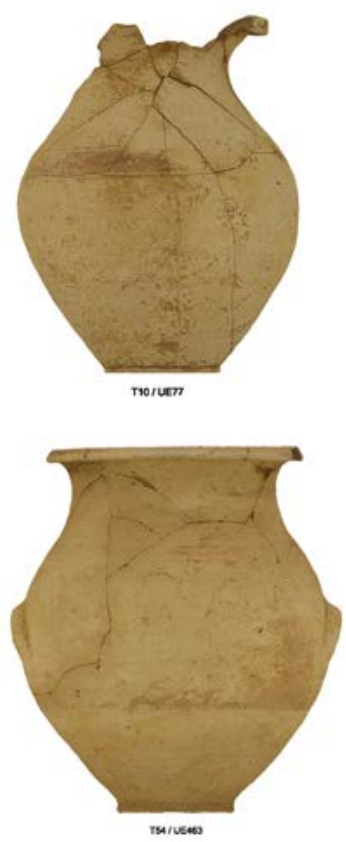

$20 / 4 \operatorname{sens}$

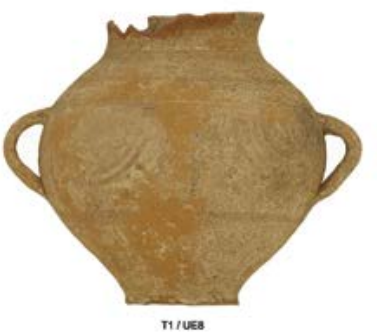

T1/40

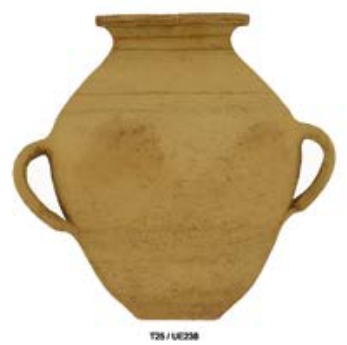

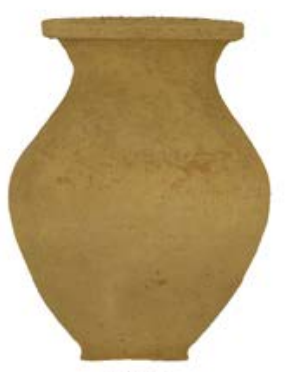

Tra/vert
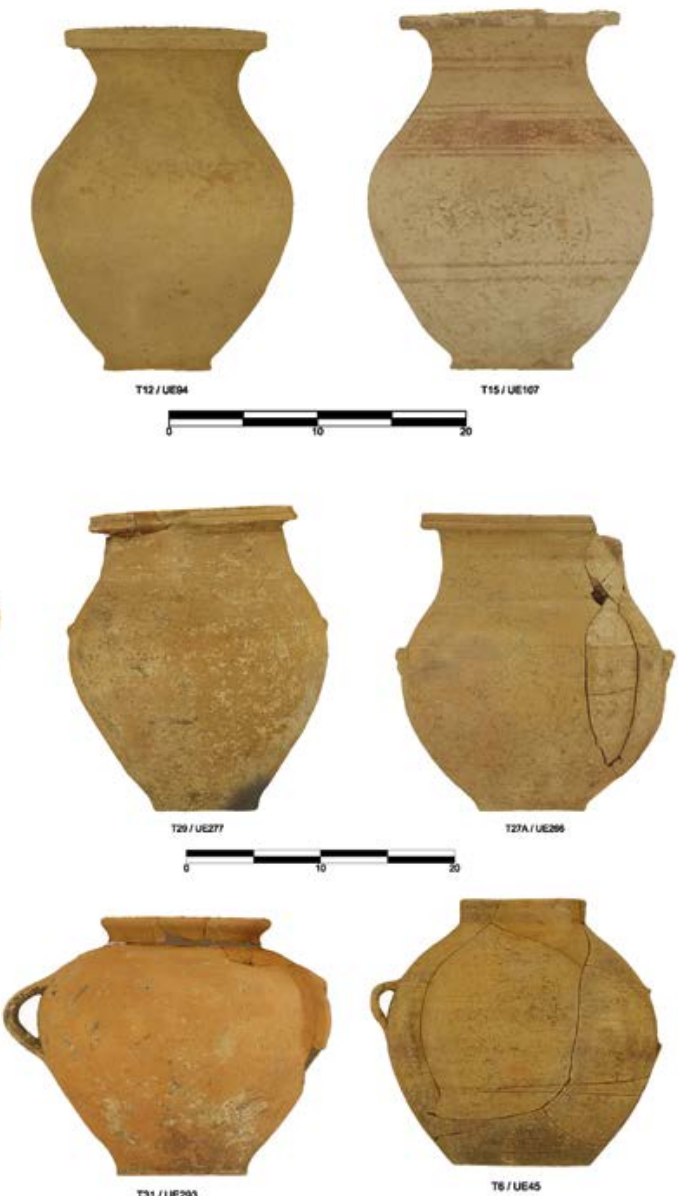

raveres

a $\mathbf{a}$ a

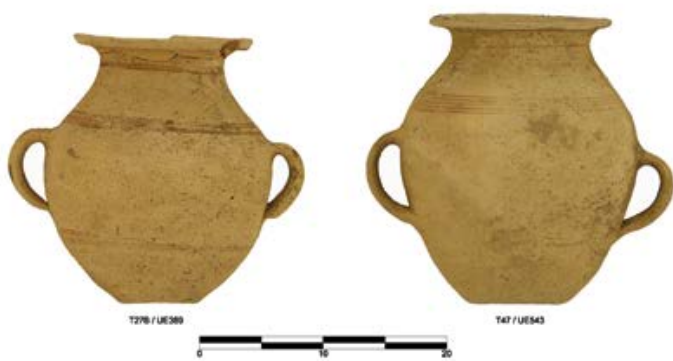

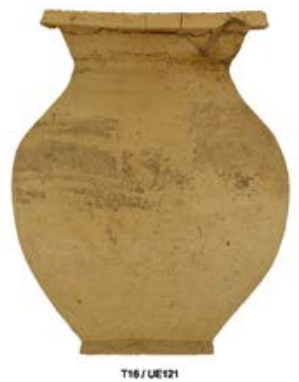
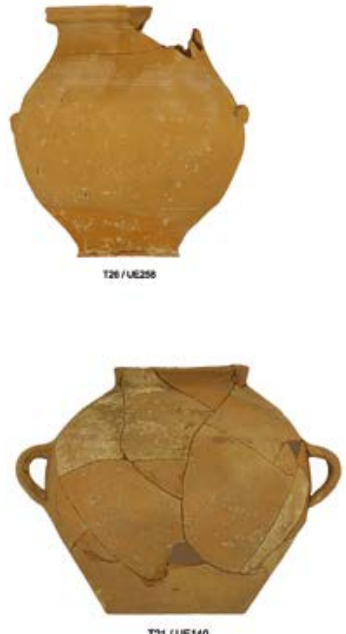

T21/UE⿰亻⿻

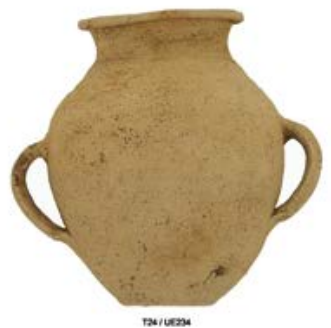

Figura 10. Llanos del Pretorio. Tipos básicos de urnas cinerarias de supuesta tradición indígena documentados en el sepulcretum (a partir de M. Rubio Valverde; montaje M. D. Ruiz Bueno).

dispuestos en fachada del Recinto L, y los apenas 12 cm conservados del ubicado en la esquina sureste del Recinto B (vid., para el caso de Segobriga, Cebrián y Hortelano 2016: 51 ss.). Presentaban sin excepción su superficie desbastada, incluso en la zona destinada a ser embutida en tierra, y ninguno de ellos tenía perforaciones para traviesas lígneas, que sí se observan en otros ejemplos del norte de Italia. Tanto en el caso de los que portaban inscritas mensurae sepulcri como en los de remate semicircular del Recinto L, su cara principal había sido primorosamente alisada.

Hablo de construcciones familiares que, con orígenes remotos en Grecia, parecen surgir en sus primeras expresiones romanas a finales de la etapa tardorrepublicana; sirvieron no solo para enterrar a los muertos sino también, con frecuencia, para quemarlos, y agluti- 


\begin{tabular}{|c|c|c|c|c|c|}
\hline U.E. & DESCRIPCIÓN & RECINTO & $\begin{array}{c}\text { ALTURA } \\
\text { (POTENCIA) }\end{array}$ & LARGO & ANCHO \\
\hline 174 & Esquina sureste & A & 0.32 & 0.71 & 0.54 \\
\hline 178 & Esquina sureste & $\mathrm{B}$ & 0.12 & 0.66 & 0.71 \\
\hline 220 & Esquina noroeste & \multirow{3}{*}{$\mathrm{C}$} & 1.00 & 0.70 & 0.57 \\
\hline 218 & Esquina noreste & & 0.33 & 0.42 & 0.54 \\
\hline 216 & Esquina suroeste & & 0.26 & 0.75 & 0.61 \\
\hline 192 & Esquina noroeste & \multirow{4}{*}{$\mathrm{F}$} & 1.00 & 0.71 & 0.46 \\
\hline 190 & Esquina noreste & & 1.22 & 0.57 & 0.53 \\
\hline 188 & Esquina sureste & & 1.37 & 0.75 & 0.55 \\
\hline 244 & Cipo que flanquea la entrada del recinto & & 0.98 & 0.60 & 0.44 \\
\hline 186 & Esquina noroeste & \multirow{4}{*}{ G } & 0.84 & 0.56 & 0.46 \\
\hline 184 & Esquina noreste & & 0.34 & 0.55 & 0.53 \\
\hline 182 & Esquina suroeste & & 1.67 & 0.60 & 0.54 \\
\hline 180 & Esquina sureste & & 1.02 & 0.60 & 0.52 \\
\hline 168 & Esquina noroeste & \multirow{3}{*}{$\mathrm{H}$} & 0.74 & 0.66 & 0.37 \\
\hline 166 & Esquina noreste & & 0.82 & 0.70 & 0.44 \\
\hline 170 & Esquina suroeste & & 1.20 & 0.69 & 0.42 \\
\hline 37 & Esquina noroeste & I & 0.80 & 0.50 & 0.50 \\
\hline 86 & Esquina sureste & $\mathrm{J}$ & 0.70 & 0.80 & 0.60 \\
\hline 246 & Esquina suroeste & \multirow{2}{*}{$\mathrm{K}$} & 0.30 & 0.70 & 0.62 \\
\hline 248 & Esquina sureste & & 0.65 & 0.70 & 0.56 \\
\hline 357 & Línea de fachada & \multirow{2}{*}{$\mathrm{L}$} & 1.70 & 0.80 & 0.39 \\
\hline 310 & Línea de fachada & & 1.64 & 0.82 & 0.65 \\
\hline 308 & Esquinas sureste/suroeste & $\begin{array}{c}\mathrm{L} / \mathrm{M} \\
\text { (compartido) }\end{array}$ & 1.11 & 0.61 & 0.39 \\
\hline 306 & Línea de fachada & \multirow{2}{*}{ M } & 0.52 & 0.50 & 0.33 \\
\hline 304 & Tumba 60 & & 1.37 & 0.68 & 0.56 \\
\hline 4 & Esquina noreste & \multirow{6}{*}{$\mathrm{N}$} & 0.81 & 0.64 & 0.49 \\
\hline 156 & Esquina noroeste & & 0.74 & 0.58 & 0.50 \\
\hline 158 & Lateral este & & 1.06 & 0.73 & 0.40 \\
\hline 160 & Lateral oeste & & 1.03 & 0.57 & 0.42 \\
\hline 162 & Esquina sureste & & 0.83 & 0.74 & 0.40 \\
\hline 164 & Esquina suroeste & & 0.84 & 0.72 & 0.45 \\
\hline 312 & Esquina sureste & \multirow{2}{*}{$\mathrm{O}$} & 0.47 & 0.86 & 0.39 \\
\hline 314 & Fachada lateral & & 0.50 & 0.58 & 0.52 \\
\hline 226 & Esquina suroeste & \multirow{2}{*}{$\mathrm{P}$} & 0.73 & 0.66 & 0.57 \\
\hline 228 & Esquina sureste & & 0.45 & 0.50 & 0.50 \\
\hline
\end{tabular}

Figura 11. Llanos del Pretorio. Medidas de los cipos documentados, por recintos. Alturas totales (elaboración M. D. Ruiz Bueno). 
naron además todo lo necesario para garantizar los funerales y las ceremonias conmemorativas (Hesberg 2005). Los más antiguos de Córdoba, con alzados de adobe y tapial sobre zócalos pétreos, fueron documentados bajos los monumentos funerarios de Puerta de Gallegos, con una cronología un tanto imprecisa de la primera mitad del siglo I a. C.; pero el tipo, ya de mampostería -aun cuando no cabe descartar eventualmente alzados de barro-, alcanza plena carta de naturaleza y máximo desarrollo en época augustea, y sigue apareciendo hasta principios o incluso mediados del siglo II, casi siempre, en esta última fase, de sillería.

Es muy posible que los recintos funerarios reflejen en Córdoba la misma o similar evolución que en Roma, donde surgen hasta cierto punto para "esconder", aislar, proteger o incluso realzar las tumbas monumentales, hasta erigirse con el tiempo en estructuras funerarias con entidad propia. Habrían pasado de simples acotados señalizados mediante cipos de piedra y madera, cuerdas, vallas de variada morfología o vegetación, a recintos de adobe primero y obra después con o sin puerta, de mayor o menor altura según albergaran o no monumentos funerarios, y con o sin ustrina interiores, hasta llegar finalmente a expresiones más monumentalizadas que incorporan la sillería y, en línea con el desarrollo del ritual, adquieren un carácter más cerrado. Obviamente, esto no evitó que unos y otros coexistieran siempre con loci abiertos. Por otra parte, aun cuando los recintos y acotados cordubenses acogieron sobre todo enterramientos de cremación, no faltan en ellos las inhumaciones, en particular infantiles; y a veces de cronología más tardía. Curiosamente, en algunos recintos del norte de Italia los enterramientos infantiles y/o femeninos, con frecuencia asociados, llegan a alcanzar el $50 \%$ del total (Cipriano 2005: 280), hecho observado también en conjuntos cordobeses como el Marrubial (Penco $2004^{10}$ ); por el momento solo una línea más de trabajo.

Un proceso así podría explicar sin dificultad la compleja casuística constructiva -entendida siempre en perspectiva diacrónica-, observada por ejemplo en conjuntos como Camino Viejo de Almodóvar, Avda. de las Ollerías, o Llanos del Pretorio, si bien no cabe descartar saltos en el proceso, o coexistencias, que deberá perfilar poco a poco la arqueología. Recintos volverían a utilizarse en la ciudad durante la etapa tardorromana, pero ya en el marco de una nueva concepción del mundo funerario gobernada por el cristianismo. Entre otros muchos casos, baste con destacar

${ }^{10}$ Penco, R. 2004: Informe de la A.A.P. del Marrubial, Esq. Poeta Solís y Vázquez Venegas de Córdoba, Informe inédito conservado en la Delegación Provincial de Cultura de la Junta de Andalucía en Córdoba, donde fue consultado. ahora la Manzana de Banesto (Ruiz Osuna 2007a: 64), o el Parque Infantil de Tráfico (Cerrato 2018, con bibliografía anterior).

Esta particular forma de expresión funeraria supo aprovechar a la perfección el escaparate público, de visibilidad, autorrepresentación, facilidad de acceso, prestigio y también vanidad (Gregori 2005: 164), que le ofrecían las vías principales; y cuando no pudieron acceder a ellas se sirvieron de diverticula creados $e x$ profeso, en una racionalización del espacio cementerial que va quedando progresivamente en evidencia (vid. al efecto Fig. 4). No obstante, en Córdoba, como en la propia Roma -donde tampoco se han detectado preferencias gentilicias por una vía u otra- (Gregori 2005: 94 ss.), y con excepción siempre de la necrópolis meridional, de casuística diferente (vid. al respecto Vaquerizo 2010), no se aprecian diferencias significativas en cuanto a las medidas de acotados y recintos en función de la vía elegida o la distancia del sepulcretum a la ciudad.

Una de las líneas prioritarias de investigación para el futuro habrá de ser, precisamente, la mejor definición del entramado viario que rodeó a la urbe, dado que hasta la fecha, salvo pequeños tramos de morfología y anchura muy diversas bien documentados en Huerta de San Rafael, Puerta de Gallegos, Ronda de Tejares 6, Huerta de los Tejares frente a Puerta de Osario, y calle San Pablo, el trazado tradicionalmente propuesto es en esencia hipotético (Ruiz Bueno e. p.) (Fig. 12); y el recorrido más problemático es el atribuido a la actual Avda. de las Ollerías, ya que la muralla medieval alteró bastante la topografía de la zona. De ahí las dificultades para interpretar correctamente el contexto topográfico del sepulcretum exhumado al final de la misma.

A juzgar por algunos restos localizados siempre de manera descontextualizada, en determinados recintos de obra sus muros interiores pudieron ser estucados y pintados (así podría haber ocurrido en Camino Viejo de Almodóvar, y quizás también en Llanos del Pretorio), o por lo menos mostrar cierto afán decorativo, como se percibe en el Recinto F de este último con la simulación sobre el enfoscado de un despiece de sillería; elementos que en cualquiera de los casos soportarían mal el calor provocado por la disposición reiterada de las piras funerarias dentro de sus muros. Por lo que se refiere a las pavimentaciones interiores, lo habitual fue que quedaran regularizadas mediante una capa de picadura de sillar. Sin embargo, parece demostrado que también pudo haberlas de losas de calcarenita, opus caementicium, opus latericium (quizás spicatum), e incluso opus sectile. Estas cuatro últimas modalidades han sido identificadas en Camino Viejo de Almodóvar. Más allá de estos datos no tenemos constancia firme de que los recintos cordubenses conocidos hasta la fecha, en cualquiera de sus modali- 


\begin{tabular}{|l|c|}
\hline $\begin{array}{c}\text { Ubicación actual y denominación por la comunidad } \\
\text { científica }\end{array}$ & Anchura de la vía \\
\hline Ronda de los Tejares 6-Reyes Católicos 17 & Al menos 5,20 m \\
\hline C. Abderramán III 10 & $4,43 \mathrm{~m}$ \\
\hline Av. de América 5 & $2,30 \mathrm{~m}$ (de media) \\
\hline C. Muro de la Misericordia 8A & $6,30 \mathrm{~m}$ (de media) \\
\hline Llanos del Pretorio & 2,40 \\
\hline Glorieta Ibn Zaydun & 6 - 7,30 m (aprox.) \\
\hline C. San Pablo 17 (Vía Augusta) & $5,90 \mathrm{~m}$ \\
\hline C. Muñices 33 (Vía Augusta Vetus) & $8,8 \mathrm{~m}$ (4 corresponden a la calzada; 2,40 m a los acerados) \\
\hline
\end{tabular}

Figura 12. Síntesis de los tramos de vías bien conocidos en la ciudad de Córdoba para época altoimperial (elaboración M.D. Ruiz Bueno).

dades, incorporaran aparato ornamental. Nada que ver, por tanto, con lo observado por ejemplo en otras necrópolis de la Cisalpina, donde se reservaba a la decoración "il ruolo di esplicitare il rango sociale del propietario del sepolcro" (Tirelli 2005: 257).

Prueba determinante de la construcción planificada y simultánea de estas baterías de recintos es que en algunos casos comparten medianeras, como se pudo comprobar en La Constancia o también en Ollerías; pero esta circunstancia no siempre se da, ni en Córdoba, ni en otras zonas del Imperio (Sartori 2005: 166; Tirelli 2005: 254 ss.). Esta premisa, sumada al mal estado de conservación en el que nos ha llegado la mayor parte de ellos, y las limitaciones metodológicas con las que en muchos casos han sido excavados (de forma particular en ciudades como Córdoba), hace más complicado interpretar arqueológicamente las respectivas dinámicas, o la imagen que tales sepulcreta pudieron ofrecer en cada una de sus fases.

Finalmente, como ha sido bien observado en necrópolis de Hispania o del occidente del Imperio, incluida la propia Roma, al abrigo de los recintos funerarios cordobeses se dispusieron con frecuencia por el exterior otros muchos enterramientos que utilizaron rito y morfología similares, y ustrina de uso posiblemente colectivo, si bien por el momento resulta imposible determinar el grado de relación que tales individuos tuvieron con los propietarios de aquellos. En Altinum tales zonas fueron reservadas a esclavos y libertos de los dueños de los recintos inmediatos (Cresci Marrone 2005: 314).

\subsection{OTROS EJEMPLOS HISPANOS}

Más allá de Roma, Ostia o las ciudades del norte de Italia y la Galia (vid. por ejemplo al efecto Heinzelmann
2000; Christol y Janon, 2002, o los numerosos trabajos sobre el tema contenidos en Cresci Marrone y Tirelli 2005), donde en algún caso la racionalización del espacio funerario remonta a época prerromana (Gambacurta et alii 2005), y los recintos funerarios constituyen una de las expresiones funerarias más características y significativas de la etapa tardorrepublicana y el Alto Imperio hasta el punto de inaugurar la aparición de la epigrafía (Cresci Marrone 2005: 306 ss.), en Hispania contamos también para ellos con algunos paralelos de interés, entre los cuales Segobriga y Barcino.

En Segobriga (Abascal et alii 2008; Cebrián y Hortelano 2016), la necrópolis septentrional había revelado hace años un paisaje funerario de mediados del siglo I d. C. presidido por grandes recintos alineados a ambos márgenes de la vía, con una única referencia epigráfica conservada, que aludía a un locus cuadrado de 15 pies de lado (Cebrián, Hortelano 2016: 53, nota 11). Con posterioridad, la excavación de su necrópolis noroccidental, bajo el circo, dejó de nuevo al descubierto, ahora ya de forma sistemática y exhaustiva, una topografía y una dinámica funerarias muy similares a la del Pretorio, si bien de cronología algo posterior, centrada entre época tardoagustea y mediados del siglo II d. C. El sepulcretum se organizó en torno a una vía principal de entre 6 y 10 pies de anchura según el tramo, y dos caminos secundarios, y usó como rito prácticamente exclusivo la cremación, con un claro predominio entre los enterrados de esclavos y de libertos, si bien los abundantes restos de tumbas monumentales recuperados no muy lejos, con representación epigráfica de algunos magistrados, permiten suponer un espectro social más variado.

Los recintos dispuestos en el lado oriental de la vía no compartían medianeras, pero sí muro de fachada, de forma similar a como ocurre en Ollerías y en Llanos del Pretorio con el muro trasero meridional; hecho 
que, junto a la aparición de un terminus con el clarificador titulus C(ippus).PR(imus), se ha considerado prueba determinante de la parcelación previa del terreno con fines funerarios (Cebrián y Hortelano 2016: 41 ss.) (Fig. 13). Su lectura alternativa como $C($ ardo) $P($ rimus $)$ ofrecería una sugerente conexión con el $V \cdot I$. $C$. de Avda. de Ollerías, quizá también, como ya vimos, referencia catastral.

A tenor de la disposición de las numerosas estelas documentadas (algunas de ellas in situ), no se descarta además la existencia de acotados definidos por vallas o cercas de madera; un paisaje sepulcral en el que no faltan un gran ustrinum colectivo -si bien hubo también quemaderos en el interior de los propios recintos-, y monumentos de diverso porte.

Como en los seplucreta cordubenses, los seis recintos documentados fueron delimitados con termini cuádruples fechados a mediados del siglo I d. C.: dos en fachada, eventualmente con indicatio pedaturae, y dos en la parte posterior, sin ella; pero sus medidas, menos estandarizadas que en Córdoba, solo coinciden in agro, como en Avenida de las Ollerías: 15 pies, mientras in fronte oscilan entre 15 -Recintos 1 y 3 , indicados sobre piedra únicamente en el segundo-, 17,5 -Recintos 4 y 5 , con reflejo epigráfico en el primero-, y 25 pies -Recinto 1, sin constatación epigráfica- (Abascal et alii 2011: 187 ss.; Cebrián y Hortelano 2016: 47 ss., figs. 309 y 310). En el Recinto 4, dos cipos de cabecera redondeada señalaban en fachada las mensurae sepulcri in fronte -In . f(ronte) . p(edes) / XVIIS(emis) $-^{11}$, y uno más en la parte trasera -abriendo por tanto al interior del recinto, como también ocurría en Llanos del Pretorio-, los pies in agro. La precisión de los primeros, que llegan a especificar el medio pie, recuerda a otros casos similares de Roma, donde existe incluso algún ejemplo con la indicación de los digiti (el digitus equivalía a 1/16 parte del pie; CIL VI, 39116; Gregori 2005: 88 ss.), lo que para algunos investigadores es prueba incontestable de que se disponían en un terreno previamente planificado, al que hubieron de adaptarse de forma casi milimétrica (Zaccaria 2005: 199). El muro de fachada y los de delimitación de los recintos (solo cerrados por detrás en el caso del $n^{\circ} 1$ ) fueron construidos con base de mampostería irregular y alzado de tapial enlucido de cal por el exterior.

En Barcelona, por su parte, varias intervenciones arqueológicas recientes en el Mercado de San Antonio (Hinojo y Ribas 2017) ${ }^{12}$ han puesto al descubierto un

\footnotetext{
11 Abascal et alii2008: 51 ss., fig. 31; Abascal et alii 2011: 187 ss., n. 195-196; Cebrián y Hortelano 2016: 47 ss., figs. 44 ss, y 226, figs. 309 y 310.

${ }_{12}$ Gracias a Emiliano Hinojo y Carmen Miró por facilitarme literatura sobre este conjunto, así como la planta que acompaña a este texto.
}

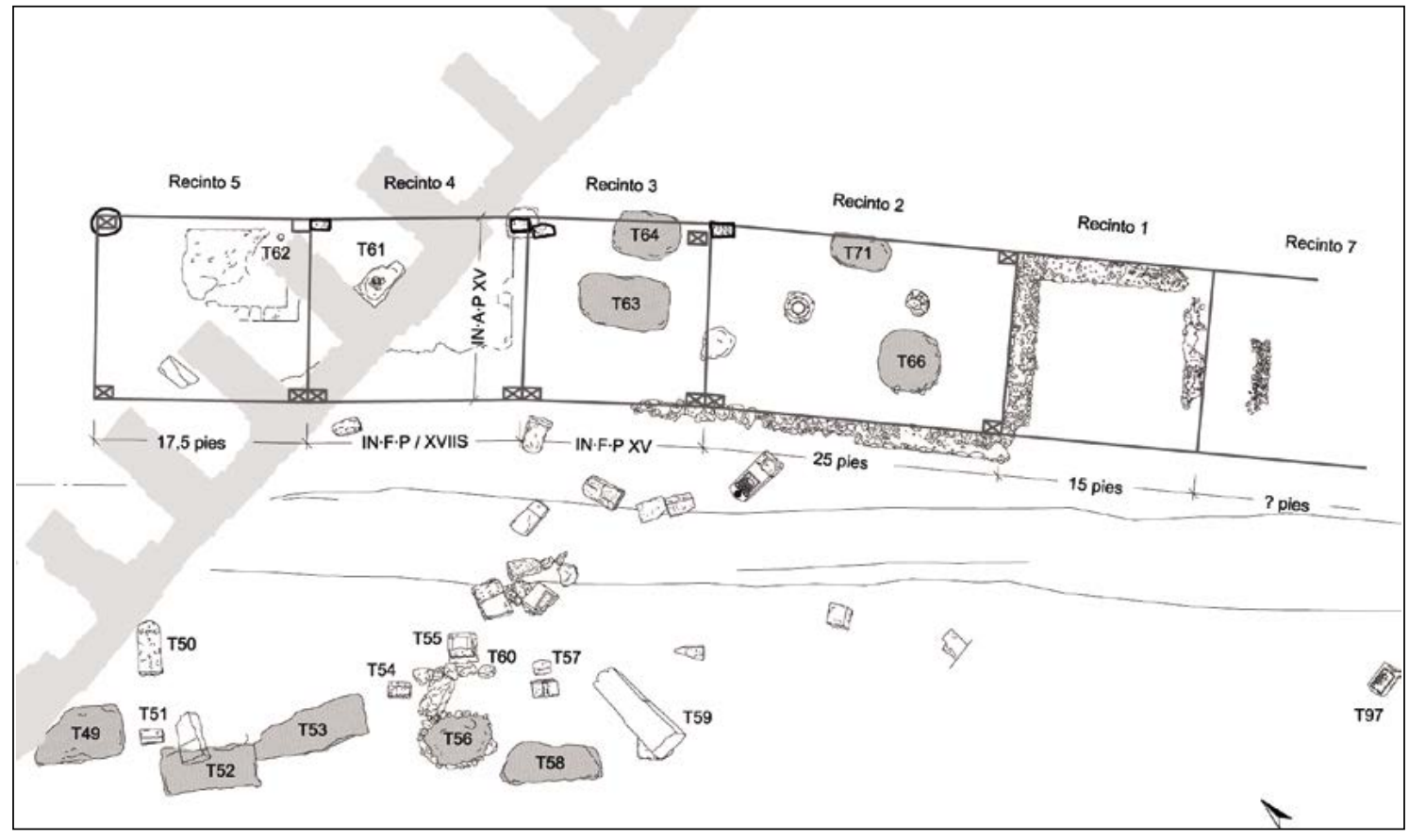

Figura 13. Segobriga. Vía funeraria en la necrópolis occidental, bajo el circo (a partir de Cebrián y Hortelano 2016, fig. 44; cortesía R. Cebrián). 
sector funerario extramuros de la ciudad, tras dar salida el cardo máximo a la via Augusta por el sudoeste, cuya conformación topográfica ofrece un paralelismo extraordinario con los sepulcreta cordobeses aquí analizados (Fig. 14). A tan importante arteria de comunicación, excavada en una cincuentena de metros, daban fachada por sus dos márgenes toda una serie de recintos a cielo abierto sin puertas conservadas, que se adosaban a los limites longitudinales de aquella: seis en el lado sur -de planta cuadrada, con lados de unos $3 \mathrm{~m}$ (10 pies), ustrina privados en cuatro de ellos, dos busta y una cupa structilis entre los tipos de enterramientos de cremación documentados-, y un número indeterminado al norte, superpuestos y con medidas más variadas, que incluían también un ustrinum y algunos busta. Varios de ellos conservaban restos de los lechos funerarios (un mínimo de ocho), con armazones internos de hierro y revestimientos de hueso tallado con relieves de temas orientalizantes, helenísticos, y báquicos, sobre los que fueron quemados los cadáveres. Solo uno de los recintos del sector meridional conservaba algo de su alzado, en opus vittatum, lo que da idea de cierta monumentalidad.

Cremación e inhumación convivieron en la necrópolis. Más en concreto se habla de trece inhumaciones repartidas a ambos lados de la vía, tres identificadas como individuos adultos, y dos como infantiles o perinatales. Sin embargo, no se especifica reparto espacial ni temporal, lo que limita la validez del dato. El complejo, que arrancaría de mediados del siglo I d. C., se habría visto colmatado por una riada a principios del siglo II, en un curioso paralelismo con Llanos del Pretorio o Avda. del Corregidor, si bien el hecho de que no quedara totalmente cubierto habría facilitado su expolio.

En Cataluña destaca también el caso de Baetulo, en cuyo suburbio occidental (Illa Fradera) fue exhumada hace algún tiempo una batería de recintos funerarios delimitada por dos muros longitudinales, con una primera fase de mediados del siglo I d. C., en los que se practicaron enterramientos de cremación y de inhumación (Antequera et alii 2010: 188 ss., fig. 12).

\section{SUPERFICIES Y SIMBOLOGÍA}

La casuística relacionada con las medidas de los recintos cordubenses conocidos hasta la fecha es amplia. Mientras la epigrafía testimonia superficies reducidas y muy uniformes, la arqueología lo hace de valores más variados y con frecuencia más altos; algo que ha sido observado también en Italia, donde los tituli conservados de época republicana no se hacen eco en absoluto de la variedad tipológica de los monumentos constatada sobre el terreno, sí reflejados en cambio de manera reiterada en los de época imperial, sobre todo en sus acepciones de locus o monumentum (Gregori 2005: 79 ss.). De ahí la necesidad de elaborar pronto en Córdoba un mapa detallado de estas tipologías funerarias que recoja dispersión, superficies, edilicia, existencia o no de epigrafía, cronología, estatus jurídico de sus propietarios y tantos otros aspectos de interés, imprescindibles para entenderlas en su plena dimensión.

Por el momento (Vaquerizo y Sánchez 2008 y 2009; Vaquerizo 2010), observamos una relación de concordancia entre las dimensiones medias de los recintos documentados en la Hispania meridional y los casos conocidos para Roma y las ciudades más destacadas de Italia o de la Narbonense, donde priman los acotados de entre $10 \times 10$ y $15 \times 15$ pies (Christol y Janon 2002: 121), con algunas excepciones como la de Altinum, de media más alta (Buonopane y Mazzer 2005: 331 ss.). Sin embargo, esta notable analogía no debe interpretarse de modo automático como fruto del proceso de imitatio Urbis desarrollado en otros aspectos por los talleres epigráficos provinciales. El tamaño del locus dependería siempre de la disponibilidad de terreno por parte de la ciudad (lo que no quiere decir que todo el suelo perteneciera a la curia, o todas las "promociones" fueran de iniciativa pública; por el contrario, muchas tierras serían lotizadas y vendidas por particulares) y económica por parte de la familia -quizás también de la costumbre en origen, de la moda o la oferta-, y la indicación o no de la pedatura -grabada en piedra, al menos- de la decisión personal $\mathrm{y}$, de nuevo, la tradición gentilicia; aparte, por supuesto, de la época, las circunstancias y las peculiaridades locales concretas: presión demográfica, necesidad o demanda de suelo, mercado y precios, existencia o no en las leges municipales de disposiciones reguladoras de la distribución, medidas y protección de los loci sepulcrales, incidencia de las usurpaciones de tumbas, etc. (vid.a este respecto López Melero y Stylow 1995: 230; Purcell 1987: 33 ss.).

No se conservan muchas referencias de precio, que hasta donde testimonian las inscripciones en Roma oscilaron entre los 180 sestercios por los que un tal Celsius vendió en la vía Latina un acotado de $6 \times 3$ pies, los 5.000 que pagó Trebonia Salvia, liberta de Gaio, por un área de $12 \times 18$ pies, y los 16.000 que desembolsó otra mujer de nombre indeterminado por un locus de solo $12 \times 12$ pies, estos dos últimos de procedencia y ubicación desconocidas (Gregori 2005: 96). Obviamente, sería temerario extrapolar esta realidad al caput Baeticae, pero puede servir como elemento de contraste.

La proliferación de estos termini y de las mensurae sepulcrorum que con frecuencia los acompañan testi- 


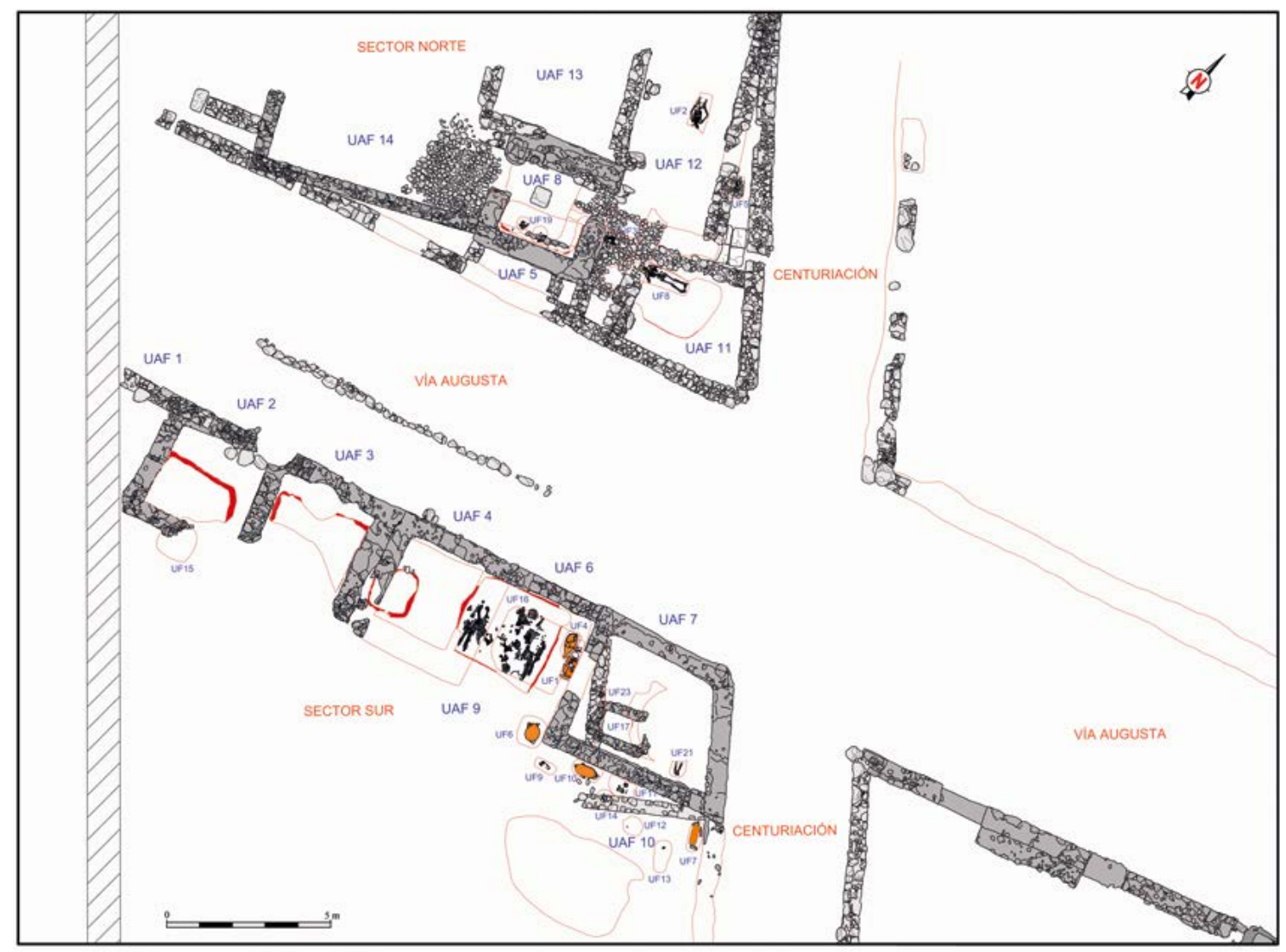

Figura 14. Mercado de San Antonio (Barcelona). Planta de la intervención arqueológica (cortesía E. Hinojo y C. Miró).

monia en principio un alto valor del terreno suburbano destinado a fines funerarios, compartimentado en lotes de mayor o menor tamaño mediante procesos de planificación topográfica, al tiempo que una preocupación profunda por dejar evidencia social, escrita e imperecedera de la integridad del respectivo locus. Dado el carácter prioritario de la fachada como elemento más visible y apto para la representación, las medidas in fronte suelen primar -o por lo menos equipararse- sobre las in agro, pero no faltan casos en los que tal ecuación se invierte, caso de Aquileia, donde en la mayoría de los recintos documentados la relación in fronte/in agro es de 1:2 (Zaccaria 2005: 204; otros ejemplos en Cresci Marrone y Tirelli 2005). Ni siquiera en este aspecto pueden, pues, hacerse afirmaciones absolutas.

Al dejar constancia pública de las medidas del locus se estaban fijando de forma expresa y con vocación de eternidad, ante este mundo y el otro, los límites del espacio para la muerte, que quedaba de paso bien diferenciado del destinado a los vivos (Orlandi 2004: 383). Buscaba con ello el comitente dotar a su tumba de personalidad jurídica pública confor- me al ius civile, que reforzaba su carácter de res religiosa amparada implícitamente por el ius pontificium, aun cuando materializada en el ius funerum, de la mano del rito legítimo (Lazzarini 2005: 50). Todo ello, en un intento doble de mantener su integridad para siempre, por cuanto la protección legal solo se podía ejercer si las medidas y el perímetro del locus o del monumento estaban rigurosamente definidos (Zaccaria 2005: 198), garantizando de paso la memoria, y de evitar por vía física y jurídica la tan temida violatio sepulcri (Liguori 2005: 158). Algo que no siempre se consiguió, a pesar de tanta precaución a nivel privado, y de la vigilancia, control y tutela de los espacios funerarios periurbanos por parte de la curia.

\subsection{Perfil social de los usuarios}

Aun cuando hace sesenta años M. Floriani Squarciapino (1958: 234) relacionó los recintos funerarios de las necrópolis ostienses con libertos, comerciantes, 
artesanos, profesionales liberales, apparitores y plebeyos en general, como después han puesto también en evidencia el reflejo epigráfico y los estudios realizados en algunas de las más conspicuas necrópolis romanas de la mitad occidental del Imperio incluida la propia Roma (Gregori 2005: 98 ss.) el uso de estas modalidades de sepultura fue común en realidad a los más diversos sectores sociales -incluidos algunos miembros de las clases senatorial y ecuestre documentados por ejemplo en el ager de Aquileia (Zaccaria 2005: 209), en claro contraste con ingenui, esclavos y una mayoría de libertos-, sin que el precio del suelo y la posible especulación urbanística, o el tamaño de su superficie, puedan o deban por obligación ser entendidos como indicio cuantitativo y económico, o cualitativo y social de los usuarios, de su carácter individual -un solo enterramiento- o familiar y colectivo (Cenerini 2005: 139; Sartori 2005: 166 ss.; Campedelli 2005: 179; Buonopane y Mazzer 2005: 333 ss.). En los dos conjuntos cordobeses analizados la única referencia epigráfica alude a una sierva o posible liberta, Bassa, pero su epitafio le fue dedicado por un ingenuus, lo que en el fondo no resuelve nada.

Tal vez por eso la verdadera clave habría que buscarla en su ubicación, junto a vías principales y cruces de las mismas, vías funerarias sensu stricto, o las respectivas propiedades privadas de cada familia. Sobre un recinto previo se construye en Colonia Patricia el túmulo septentrional de la Puerta de Gallegos, erigido junto a la porta urbica occidentalis -que daba salida al decumano máximo- por una familia perteneciente como poco al ordo equester. Es muy significativo por otra parte que los más importantes sepulcreta del tipo aquí analizado se ubicaran en la necrópolis septentrional de la ciudad, lo que resulta tentador poner en relación con el hecho de que ese mismo suburbio fuera elegido por las principales societates mineras para ubicar sus officinae y quizás también muchas de sus instalaciones. Serían, pues, foco de atracción de itálicos que traerían consigo las modas funerarias vigentes por esas fechas en Roma y su entorno, agentes activos de romanización como ocurrió en el norte de Italia (Cresci Marrone 2005: 307). Con todo, a día de hoy resulta muy difícil interpretar conjuntos como Llanos del Pretorio, La Constancia o Avenida de las Ollerías desde el punto de vista de la propiedad o de su adscripción social y económica-vid. al respecto los resultados recogidos en Vaquerizo y Sánchez 2008 y 2009-, entre otras razones por la parquedad al respecto de la epigrafía, limitada en la mayor parte de los casos a la definitio pedaturae.

Muy posiblemente lo normal fue la compra privada de carácter individual en vida con intención de destinar el acotado a tumba familiar. Así queda refle- jado de hecho en multitud de tituli procedentes del norte de Italia y la propia Roma, donde la casuística es muy amplia (Gregori 2005: 96 ss.). No obstante, fue también muy frecuente la adquisición de acotados funerarios en sociedad, con parientes, amigos, colegas de profesión o miembros de collegia y sodalitates, así como la posterior compraventa de parte o de todo el espacio, la cesión, la nueva compartimentación e incluso la usurpación parcial o total de la tumba o el locus, con los contenciosos subsiguientes (Zaccaria 2005: 203 ss. y 205 ss.; Cresci Marrone 2005: 311 ss.; Buonopane y Mazzer 2005: 327 ss.). Y no faltaron como ya comenté los actos de evergetismo.

Todo esto debió generar en las ciudades un complejo entramado de relaciones familiares, económicas, de amistad o de conveniencia, que deben ser entendidas en perspectiva diacrónica y tendrían un reflejo evidente y muchas veces explícito en esos mismos espacios funerarios (vid. Buonopane y Mazzer 2005: 327 para el caso de Altinum). Sirva como ejemplo el sepulcro pompeyano de Publius Visonius Phileros, Augustalis, que construyó en el interior de su propio recinto junto a Porta Nocera la tumba para su familia, su patrona, Vesonia, hija de Publius, y un amigo, Marcus Orfellius Faustus, que lo acabaría traicionando $($ AE 1964, $160=$ AE 1986, 166b = AE 2006: 291; Berry 2009: 96 ss.; Andringa 2013: 996 ss.; Campbell 2015: 269; Porter 2008) ${ }^{13}$.

\subsection{Cronología y Perspectivas de FUturo}

En Roma, la utilización de cipos con indicatio pedaturae como forma incontestable de fijar la superficie del locus está bien atestiguada desde los años finales del siglo II a. C. El interés por hacerlo se mantendrá prácticamente durante toda la etapa imperial, pero el uso a tal fin de los cipos pierde fuerza en la segunda mitad del siglo I d. C., para acabar desapareciendo en beneficio de la construcción de recintos más monumentales cuyos muros hacían ya innecesaria la fijación por escrito de aquellas, limitadas en el mejor de los casos a estelas y lastras marmóreas. En Córdoba, la práctica es detectada desde finales del siglo I a. C., aunque podría haber existido desde antes, y desaparece muy a principios del siglo II d. C., en coincidencia también con la construcción de recintos en sillería de muros más altos y fachadas presuntamente monumentales, en ningún caso conservadas, que incorporan a su vez cambios sustanciales en el ritual, bien estudiados en otras zonas y por numerosos auto-

\footnotetext{
${ }^{13}$ Gracias de nuevo a S. García-Dils por ayudarme con estas y otras referencias.
} 
res (Gregori 2005: 106 ss.). Todo ello ligado más a las modas y la evolución de la epigrafía sepulcral, de cuya mano vendría enseguida el éxito de los altares funerarios, que a eventualidades como la aparición de un nuevo elemento coercitivo destinado a garantizar la integridad del locus y evitar la violatio sepulcri: las multas funerarias (López Melero y Stylow 1995: 233 ss.; Stylow y López Melero 1995; Saquete 2002; Stylow 2002a: 361 ss., y 2002b: 174-175).

Se entiende así la conveniencia de seguir profundizando en un tema evidenciado arqueológicamente en Hispania hace solo unos años, en aras de perfilar la ritualidad, la evolución estructural de los recintos, la morfología y casuística específica de las tumbas, o el posible abanico de relaciones sociales y familiares entre quienes ocupan el interior de los acotados o los recintos construidos, y aquellos otros que se vieron relegados al exterior de los mismos. También, de aquilatar si siglo y medio después de que se introdujera en las provincias hispanas la costumbre de parcelar el espacio funerario fijando los lotes mediante cipos con o sin definitio pedaturae, habían desaparecido ya la necesidad jurídica de carácter público y la preocupación privada por garantizar la integridad del monumento y la memoria personal que en principio la generaron -importada sin duda de Italia de la mano de colonos, comerciantes, mineros y quizá también militares-, o, por el contrario, debemos pensar en un cambio de hábitos epigráficos y familiares ligados a la volubilidad de las modas, muy presentes en el mundo de la muerte como escaparate último de vanitas, expresión anhelante de perennitas y, por supuesto, garantía consciente de rituales debidamente atendidos.

\section{BIBLIOGRAFÍA}

Abascal, J. M., Alföldy, G. y Cebrián, R. 20I I: Segobriga V. Inscripciones romanas. 1986-2010, Madrid.

Abascal, J. M., Almagro-Gorbea, M., Cebrián, R. y Hortelano, I. 2008: Segóbriga 2007. Resumen de las intervenciones arqueológicas, Cuenca.

Andringa, W. 2013: "Défunts et visiteurs des enclos. Les inscriptions", W. van Andringa, H. Duday y S. Lepetz (eds.), Mourir à Pompéi. Fouille d'un quartier funéraire de la nécropole romaine de Porta Nocera (2003-2007), EFR 481, Rome, 9911010.

Antequera, F., Padrós, P. y Rigo, A. 2010: "El suburbium occidental de Baetulo", D. Vaquerizo (ed.), Las áreas suburbanas en la ciudad histórica. Topografía, usos, función, MgAC 18, Córdoba, 173210
Antico, M. 1997: "Locus datus decreto decurionum. Riflessioni topografiche e giuridiche sul suburbium attraverso i tituli funerari", Epigraphica LIX, 205-224.

Baldasarre, I. 2002: "La necropoli dell'Isola Sacra", D. Vaquerizo (ed.), Espacio y usos funerarios en el Occidente romano, Córdoba, Vol. II, 11-26.

Bennett, D. y Timm, R. M. 2016: “The dogs of Roman Vindolanda, Part II: Time-stratigraphic occurrence, ethnographic comparison and biotype reconstruction", Archaeofauna 25, 107-126.

Berry, J. 2009: Pompeya, Madrid.

Bodson, L. (ed.) 2001: La sépulture des animaux: Concepts, usages et pratiques à travers le temps et l'espace. Contribution à l'étude de l'animalité, Liège.

Buonopane, A. y Mazzer, A. 2005: "Il lessico della pedatura e la suddivisione dello spazio funerario nelle iscrizioni di Altino”, G. Cresci Marrone y M. Tirelli (eds.), "Terminavit sepulcrum": i recinti funerari nelle necropoli di Altino, Atti del Convegno, Roma, 325-341.

Cafiero, F. 2005: "Un nuovo recinto funerario dalla necropoli sud-occidentale della via Annia", G. Cresci Marrone y M. Tirelli (eds.), "Terminavit sepulcrum": i recinti funerari nelle necropoli di Altino, Atti del Convegno, Roma, 289-295.

Calza, G. 1940: La necrópoli del Porto di Roma nell'Isola Sacra, Roma.

Campbell, V. L. 2015: The Tombs of Pompeii. Organization, Space, and Society, New York-London.

Campedelli, C. 2005: "L'indicazione della pedatura nelle iscrizioni funerarie romane di Verona e del suo agro", G. Cresci Marrone y M. Tirelli (eds.), "Terminavit sepulcrum": i recinti funerari nelle necropoli di Altino, Atti del Convegno, Roma, 175183.

Cebrián, R. y Hortelano, I. 2016: Segobriga VI. La necrópolis noroccidental de Segobriga (Saelices, Hispania Citerior): arquitectura funeraria, organización espacial y cronología, Cuenca.

Cenerini, F. 2005: "L'indicazione della pedatura nelle iscrizioni funerarie romane dell'Emilia Romagna (Regio VIII)", G. Cresci Marrone y M. Tirelli (eds.), "Terminavit sepulcrum": i recinti funerari nelle necropoli di Altino, Atti del Convegno, Roma, 137-143.

Cerrato, E. 2018: "El papel del Cristianismo en la conformación de la Corduba tardoantigua y medieval", D. Vaquerizo Gil (coord.), Los barrios en la historia de Córdoba (1). De los vici romanos a los arrabales islámicos, Córdoba, 243-297.

Christol, M. y Janon, M. 2002: "Épigraphie et espaces funéraires en Gaule méridionale”, C. Landes (ed.), 
La mort des notables en Gaule romaine, Catalogue de l'exposition, Lattes, 121-126.

Cipriano, S. 2005: "I recenti della strada di raccordo: organizzazione dello spazio e aspetti della ritualità funeraria", G. Cresci Marrone y M. Tirelli (eds.), "Terminavit sepulcrum": $i$ recinti funerari nelle necropoli di Altino, Atti del Convegno, Roma, 275-288.

Cresci Marrone, G. 2005: "Recinti sepolcrali altinati e messaggio epigrafico", G. Cresci Marrone y M. Tirelli (eds.), "Terminavit sepulcrum": i recinti funerari nelle necropoli di Altino, Atti del Convegno, Roma, 305-324.

Cresci Marrone, G. y Tirelli, M. (eds.) 2005: “Terminavit sepulcrum": i recinti funerari nelle necropoli di Altino, Atti del Convegno, Roma.

De Grossi, J. 2001: "L'uso dei cani nei riti funerari. Il caso della necropoli di età imperiale a Fidene-via Radicofani", Culto dei morti e costumi funerari romani 8, Roma, 77-82.

Floriani Squarciapino, M. (coord.) 1958: Scavi di Ostia. III. Le Necropoli. Parte I. Le tombe di età repubblicana e augustea, Roma.

Gambacurta, G., Locatelli, D., Marinetti, A. y Serafini, A. R. 2005: "Delimitazione dello spazio e rituale funerario nel Veneto preromano", G. Cresci Marrone y M. Tirelli (eds.), "Terminavit sepulcrum": i recinti funerari nelle necropoli di Altino, Atti del Convegno, Roma, 9-40.

García Matamala, B. 2002: "Enterramientos con urnas de tradición indígena en Corduba", D. Vaquerizo (ed.), Espacios y usos funerarios en el Occidente romano, Córdoba, vol. II, 275-296.

García Matamala, B. 2002-2003: "Enterramientos de tradición indígena en Corduba", Anales de Arqueología Cordobesa 13-14, 251-278.

García Matamala, B. y Liébana, J. L. 2006: "Inhumaciones infantiles de tradición indígena en un sector de la necrópolis oriental de Corduba", D. Vaquerizo, J. A. Garriguet y A. León (eds.), Espacio y usos funerarios en la ciudad histórica, Anales de Arqueología Cordobesa 17 (1), 99-114.

García-Dils, S. y Rubio, M. 2018: "Tres nuevas defixiones romanas en su contexto arqueológico. $\mathrm{La}$ necrópolis de Llanos del Pretorio (Córdoba)", Anales de Arqueología Cordobesa 29, 275-292.

Gregori, L. 2005: "Definizione e misurazione dello spazio funerario nell'epigrafia reppublicana e protoimperiale di Roma. Un'indagine campione", G. Cresci Marrone y M. Tirelli (eds.), "Terminavit sepulcrum": i recinti funerari nelle necropoli di Altino, Atti del Convegno, Roma, 77-126.

Heinzelmann, M. 2000: Die Nekropolen von Ostia. Untersuchungen su den Gräberstrassen vor der
Porta Romana und an der Via Laurentina, München.

Hesberg, H. von 2005: "Il recinto nelle necropoli di Roma in età repubblicana: origine e diffusione", G. Cresci Marrone y M. Tirelli (eds.), "Terminavit sepulcrum": i recinti funerari nelle necropoli di Altino, Atti del Convegno, Roma, 59-75.

Hinojo, E. y Ribas, C. 2017: "Intervencions arqueològiques al mercat de Sant Antoni: noves dades sobre la xarxa viària, l'ocupació i l'estructuració del pla de Barcelona des d'època romana i de la fortificació abaluardada del segle XVII", Tribuna d'Arqueologia 2014-2015, 401-422.

Jiménez Díez, A. 2008: Imagines Hibridae. Una aproximación postcolonialista al estudio de las necrópolis de la Bética, Anejos de AEspA XLIII, Madrid.

Lazzarini, S. 2005: "Regime giuridico degli spazi funerari”, G. Cresci Marrone y M. Tirelli (eds.), “Terminavit sepulcrum": i recinti funerari nelle necropoli di Altino, Atti del Convegno, Roma, 47-57.

Liguori, I. 2005: "La pedatura nelle iscrizioni funerarie della Liguria e del Piemonte (Regiones IX e $X I)$ ", G. Cresci Marrone y M. Tirelli (eds.), "Terminavit sepulcrum": i recinti funerari nelle necropoli di Altino, Atti del Convegno, Roma, 157-162.

López Jiménez, A. 2010: “A.A.P. Plan Especial SC2A Parcelas 3 y 4 (Córdoba)”, Anuario Arqueológico de Andalucía 2004, vol. II, 313-325.

López Melero, R. 1997: "Enterrar en Urso (Lex Ursonensis LXXIII-LXXIV)", Studia Historica. Historia Antigua 15-16, 105-118.

López Melero, R. y Stylow, A. U. 1995: “Una pena sepulcral en favor de la res publica Aiungitanorum", Espacio, Tiempo y Forma. Serie II. $H^{a} A n$ tigua 8, 219-253.

Martínez Sánchez, R, Rubio, M., Moreno-García, M., Maldonado, A., Granados, A. y Delgado, A. 2020: "Who let the dogs in? Lap dogs, canid sacrifices and funerary practices in the Roman cemetery of Llanos del Pretorio (Cordoba, Spain)", Archaeological and Anthropological Sciences 12 (4). https:// doi.org/10.1007/s12520-020-01033-1

Martínez Sánchez, R. e. p.: "Los restos animales de la necrópolis de Llanos del Pretorio (Córdoba). Depósitos votivos, contextos sacrificiales y áreas de vertido extramuros", D. Vaquerizo, A. Ruiz y M. Rubio (eds.), El sepulcretum romano de Llanos del Pretorio (Córdoba), Bari.

Melchor, E. 1995: Vías romanas de la provincia de Córdoba, Córdoba.

Melchor, E. 2006a: "Hic ordo decrevit: honores fúnebres en las ciudades de la Bética", D. Vaquerizo, J. A. Garriguet y A. León (eds.), Espacio y usos fu- 
nerarios en la ciudad histórica, Anales de Arqueología Cordobesa 17 (1), 115-144.

Melchor, E. 2006b: "Solo publico-solo suo. Sobre la ubicación de los homenajes estatuarios en las ciudades de la Bética", Cahiers du Centre Gustave Glotz. Revue d'histoire ancienne XVII, 201211.

Moret, P., Prados, F., Fabre, J.-M., Fernández, E., García, F. J., González, F. y Jiménez, H. 2017: "La Silla del Papa: hábitat y necrópolis. Campañas 2014-2016", Mélanges de la Casa de Velázquez 47 (1), Dossier. La ville antique de Baelo, cent ans après Pierre Paris, 49-71.

Morillo, A. 2015: "Lucernas romanas en Hispania: entre lo utilitario y lo simbólico”, C. Fernández, Á. Morillo y M. M. Zarzalejos (eds.), Manual de cerámica romana II. Cerámicas romanas de época altoimperial en Hispania. Importación y producción, Madrid, 321-428.

Murillo, J. F. y Carrillo, J. R. 1999: “Aspectos de la monumentalización de las necrópolis de Colonia Patricia. El monumento funerario de Puerta de Gallegos", Ciudades privilegiadas en el Occidente romano, Sevilla, 365-378.

Murillo, J. F., Carrillo, J. R., Moreno, M., Ruiz, D. y Vargas, S. 2002: "Los monumentos funerarios de Puerta de Gallegos. Colonia Patricia Corduba", D. Vaquerizo (ed.), Espacio y usos funerarios en el Occidente Romano, Córdoba, Vol. I, 247-274.

Orlandi, S. 2004: "Heredes, Alieni, Ingrati, Ceteri. Ammissioni ed esclusioni", Libitina e dintorni. Libitina e i loci sepulcrali. Les leges libitinariae campane. Iura sepulcrorum: vecchie e nuove iscrizioni, Roma, 359-384.

Porter, J. R. 2008: “Tomb of Publius Vesonius Phileros (PN 198323 OS - ca. AD 50-60): a complex tale of friendship, betrayal, and revenge reaching to the very grave", Commemorating the Dead: Texts and Artifacts in context, Berlin-New York, 39-77.

Purcell, N. 1987: “Tomb and Suburb”, H. von Hesberg y P. Zanker (eds.), Römische Gräberstrassen. Selbstdarstellung - Status - Standard, München, 25-42.

Reusser, C. 1985: "Zur Aufstellung Römischer Grabaltäre in Aquileia“, Aquileia Nostra LVI, Aquileia, 17-142.

Reusser, C. 1987: “Gräberstrassen in Aquileia”, H. von Hesbergy P. Zanker(eds.), Römische Gräberstrassen. Selbstdarstellung - Status - Standard, München, 239-249.

Rodríguez Neila, J. F. 1991: "Espacios de uso funerario con indicación de medidas en las necrópolis romanas", Conimbriga XXX, 59-94.

Ruiz Bueno, M. D. e. p.: "El suburbium nororiental de Corduba-Colonia Patricia", D. Vaquerizo, A.
Ruiz y M. Rubio (eds.), El sepulcretum romano de Llanos del Pretorio (Córdoba), Bari.

Ruiz Osuna, A. 2005: "La via sepulcralis occidental: un ejemplo de monumentalización funeraria en Colonia Patricia Corduba", Anales de Arqueología Cordobesa 16, 79-104.

Ruiz Osuna, A. 2007a: La monumentalización de los espacios funerarios en Colonia Patricia Corduba (ss. I a. C.-II d. C.), Arqueología Cordobesa 16, Córdoba.

Ruiz Osuna, A. 2007b: "La historiografía local como herramienta de reconstrucción del mundo funerario en Colonia Patricia Corduba", Spal 16, 25-40.

Ruiz Osuna, A. 2008: Topografia y monumentalización funeraria en Baetica. Conventus Cordubensis y Astigitanus, Tesis Doctoral, Universidad de Córdoba.

Ruiz Osuna, A. 2018: "La vida más allá de la muerte: topografía, ritual y tipologías funerarias entre la Corduba tardorrepublicana y la Colonia Patricia del Pleno Imperio", D. Vaquerizo (coord.), Los barrios en la historia de Córdoba (1). De los vici romanos a los arrabales islámicos, Córdoba, 187-218.

Ruiz Osuna, A. e. p.: "Las estructuras de cremación del sepulcretum de Llanos del Pretorio", D. Vaquerizo, A. Ruiz y M. Rubio (eds.), $E l$ sepulcretum romano de Llanos del Pretorio (Córdoba), Bari.

Salinas Pleguezuelo, E. 2015: "Nuevos hallazgos exhumados en una necrópolis del sector septentrional de Córdoba (España)", Nailos. Estudios Interdisciplinares de Arqueología 2, Oviedo, 253-273.

Saquete, J. C. 2002: "Notas sobre una tumba con jardín, una multa sepulcral y el paisaje suburbano de Augusta Emerita", Madrider Mitteilungen 43, 207 219.

Sartori, A. 2005: "Uno spazio vitale per il dopo", G. Cresci Marrone y M. Tirelli (eds.), "Terminavit sepulcrum": $i$ recinti funerari nelle necropoli di Altino, Atti del Convegno, Roma, 163-174.

Sinn, F. y Freyberger, K. S. 1991: Die Grabdenkmäler. 2. Die Ausstattung des Hateriergrabes Reliefs, Mainz.

Stylow, A. U. 2002a: "La epigrafía funeraria de la Bética”, D. Vaquerizo (ed.), Espacio y usos funerarios en el Occidente Romano, Córdoba, Vol. I, 353-367.

Stylow, A. U. 2002b: "Von der Schrift der Sieger zum Sieg der Schrift. Imitation, Eigenständigkeit und Differenzierung in der epigraphischen Kultur Hispaniens", G. Urso (ed.), Hispania terris omnibus felicior. Atti del convegno internazionale, Pisa, 163-181.

Stylow, A. U. y López Melero, R. 1995: "Epigraphische Miszellen aus der Provinz Jaén, 1. Eine Grab- 
buße zugunsten der Res publica Aiungitanorum", Chiron 25, 357-386.

Taglietti, F. 2001: "Ancora su incinerazione e inumazione: la necropoli dell'Isola Sacra”, M. Heinzelmann, J. Ortalli, P. Fasold y M. Witteyer (eds.), Culto dei morti e costumi funerari romani. Roma, Italia settentrionale e province nord-occidentali dalla tarda Repubblica all'età imperiale, Internationales Kolloquium, Wiesbaden, 149-158.

Tirelli, M. 2005: "I recinti della necropolis dell'Annia. L'esibizione di status di un'élite municipale", G. Cresci Marrone y M. Tirelli (eds.), "Terminavit sepulcrum": $i$ recinti funerari nelle necropoli di Altino, Atti del Convegno, Roma, 251-273.

Vaquerizo, D. 2002: "Recintos y acotados funerarios en Colonia Patricia Corduba", Madrider Mitteilungen 43, 168-206, Taf. 23-25.

Vaquerizo, D. 2010: Necrópolis urbanas en "Baetica", Tarragona-Sevilla.

Vaquerizo, D. e. p.: "La gestión del espacio funerario en la Córdoba romana: viae sepulcrales, recintos y mensurae sepulcrorum", D. Vaquerizo, A. Ruiz y M. Rubio (eds.), El sepulcretum de Llanos del Pretorio (Córdoba), Bari.

Vaquerizo, D. y Sánchez, S. 2008: "Entre lo público y lo privado. La indicatio pedaturae en la epígrafía funeraria hispana", Archivo Español de Arqueología 81, 101-131.

Vaquerizo, D. y Sánchez, S. 2009: "Addendum al Vol. 81 AEspA 2008: Entre lo público y lo privado. Indicatio pedaturae en la epigrafía funeraria hispana. Catálogo de inscripciones", Archivo Español de Arqueología 82, 311-313.
Vaquerizo, D., Garriguet, J. A. y Vargas, S. 2005: " $L a$ Constancia”. Una contribución al conocimiento de la topografía y los usos funerarios en la Colonia Patricia de los siglos iniciales del Imperio, Arqueología Cordobesa 11, Córdoba.

Vaquerizo, D., Ruiz, A. y Rubio, M. 2019: "Una nueva vía funeraria en Colonia Patricia. El sepulcretum de Llanos del Pretorio", Zephyrus 83, 79-105.

Vaquerizo, D., Ruiz, A. y Rubio, M. (eds.) e. p.: El sepulcretum romano de Llanos del Pretorio (Córdoba), Bari.

Vargas, S. y Gutiérrez, M. I. 2006: "La necrópolis romana de la Avenida del Corregidor de Córdoba", D. Vaquerizo, J. A. Garriguet y A. León (eds.), Espacio y usos funerarios en la ciudad histórica, Anales de Arqueología Cordobesa 17 (1), 259-278.

Verzár-Bass, M. 2005: "Nota sui recinti funerari decorati in Cisalpina Orientale", G. Cresci Marrone y M. Tirelli (eds.), "Terminavit sepulcrum”: i recinti funerari nelle necropoli di Altino, Atti del Convegno, Roma, 225-237.

Zaccaria, C. 2005: "Recinti funerari aquileisi: il contributo dell'epigrafia", G. Cresci Marrone y M. Tirelli (eds.), "Terminavit sepulcrum": i recinti funerari nelle necropoli di Altino, Atti del Convegno, Roma,195-223.

Recibido: 16-05-2019

Aceptado: 10-09-2019 